\title{
Tuning Photophysical Properties in Conjugated Microporous Polymers by Comonomer Doping Strategies
}

\author{
Baltasar Bonillo, Reiner Sebastian Sprick, and Andrew I. Cooper* \\ Department of Chemistry and Centre for Materials Discovery, University of Liverpool, Liverpool L69 7ZD, United Kingdom \\ Supporting Information
}

\begin{abstract}
The photophysical properties of conjugated microporous polymers (CMPs) are tuned using an acceptor doping strategy. This allows the fluorescence of a native polyphenylene network to be controlled by introducing low loadings (0.1-5 mol \%) of an acceptor comonomer, such as benzothiadiazole (BT), bisthiophenebenzothiadiazole (TBT) and perylenediimide (PDI). Fluorescence quantum yields are around 10 times higher than analogous nonporous polymers because of avoidance of chain aggregation in the porous network. White emitting CMPs with high quantum yields are prepared using this approach. Different domain structures can be prepared by changing the addition sequence of the monomers, and this has a strong effect on the fluorescent properties. These doped porous polymers can also be used as fluorescence sensors for volatile organic compounds (VOCs).

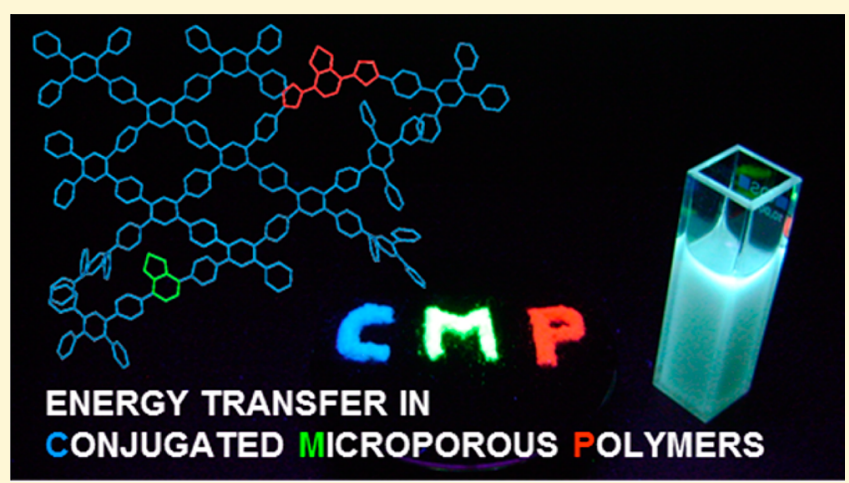

\section{CONJUGATED MICROPOROUS POLYMERS}

\section{INTRODUCTION}

Since the discovery of the first conjugated microporous polymers (CMPs) in 2007, ${ }^{1}$ there has been much interest in the synthesis and possible uses of these materials. ${ }^{2-6} \mathrm{CMPs}$ have been studied for applications such as $\mathrm{CO}_{2}$ capture ${ }^{7,8}$ and gas separation, ${ }^{9,10}$ which do not take specific advantage of the conjugation in the networks. The conjugated nature of CMPs was exploited to produce porous sensors, ${ }^{11,12}$ supercapacitors $^{13,14}$ and (photo)-catalysts. ${ }^{15-17}$ CMPs are differentiated from most other porous solids because it is possible to tune their electronic and photophysical properties, for example, by modifying the optical band gap, much as for linear, nonporous conjugated polymers. ${ }^{18,19}$ Previously, we reported the tuning of photophysical properties in CMPs by statistical copolymerization, $^{20}$ and we extended this subsequently to the control of optical band gaps in porous organic CMP photocatalysts for water splitting. ${ }^{21,22}$ In the latter study, we varied the optical band gap in the CMPs by making large changes to the monomer stoichiometry: the ratio of pyrene to phenylene monomers in the networks was varied from 0:100 to 100:0. Here, we adopt an alternative doping strategy to varying photophysical properties by using just a small amount of a comonomer dopant. This method is well-known in nonporous, linear conjugated polymers, ${ }^{23-25}$ but has so far not been demonstrated for CMPs, where the monomer stacking is quite different as a result of the extensive porosity. ${ }^{20}$

We chose CP-CMPO ${ }^{21}$ as the native polymer for these doping studies; this is the polyphenylene network that results from the Suzuki-Miyuara coupling of tetrabromobenzene (1) and benzene-1,4-diboronic acid (2) (Scheme 1). ${ }^{26}$ Our selection of this polymer was based on its high level of
Scheme 1. Synthesis of CP-CMP0, 3, 4, 5

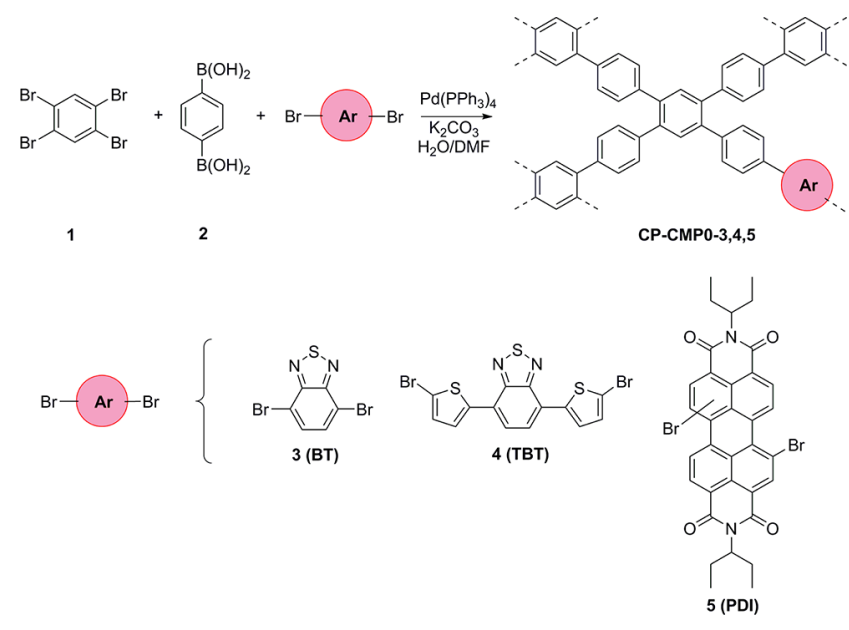

extended conjugation through the network (it comprises linear polyphenylene (PP) chains, Scheme 1) and its high degree of microporosity. Native, undoped CP-CMP0 shows a strong blue fluorescence emission. By contrast, other porous polymers with extended conjugation as tetraphenylethylene CMPs fluoresce in the yellow region at around $560 \mathrm{~nm}$, reducing the possible emission tuning range. ${ }^{27,28}$

Received: March 24, 2016

Revised: March 31, 2016

Published: March 31, 2016 
Table 1. Acceptor Monomer Feed Ratio, Apparent Brunauer-Emmett-Teller Surface Areas (SA $\mathrm{BET}_{\text {) }}$, Optical Band-Gaps, and Fluorescence and Emission Amplification of the CP-CMPs

\begin{tabular}{|c|c|c|c|c|c|c|c|c|}
\hline $\begin{array}{l}\text { polymer } \\
\text { CP-CMP }\end{array}$ & $\begin{array}{l}\text { acceptor } \\
(\mathrm{mol} \%)\end{array}$ & $\underset{\left(\mathrm{m}^{2} \mathrm{~g}^{-1}\right)}{\mathrm{SA}_{\mathrm{BET}}}$ & $\begin{array}{l}\text { optical band } \\
\text { gap }(\mathrm{eV})^{a}\end{array}$ & $\begin{array}{l}\lambda_{\text {emission }}(\mathrm{nm}) \\
\text { solid state }\end{array}$ & $\begin{array}{c}\lambda_{\text {emission }}(\mathrm{nm}) \text { PEG } \\
\text { dispersion }\end{array}$ & $\begin{array}{l}\text { amplification in solid } \\
\text { state } I_{\mathrm{AD}} / I_{\mathrm{A}}\end{array}$ & $\begin{array}{l}\text { amplification in PEG } \\
\text { dispersion, } I_{\mathrm{AD}} / I_{\mathrm{A}}\end{array}$ & $\begin{array}{l}\text { quantum } \\
\text { yield }(\%)^{b}\end{array}$ \\
\hline 0 & & 660 & 2.95 & 445 & 436 & & & 13.4 \\
\hline $3 a$ & BT (0.1) & 731 & 2.59 & 506 & 430,502 & 0.92 & 6.42 & \\
\hline $3 b$ & BT (0.5) & 592 & 2.52 & 513 & 510 & 0.64 & 2.15 & \\
\hline $3 c$ & BT (1) & 307 & 2.50 & 515 & 512 & 0.61 & 3.86 & 7.1 \\
\hline $3 d$ & BT (2) & 634 & 2.48 & 518 & 515 & 0.59 & 1.98 & \\
\hline $3 e$ & BT (3) & 506 & 2.42 & 524 & 515 & 0.48 & 1.15 & \\
\hline $3 f$ & $\mathrm{BT}(5)$ & 547 & 2.41 & 524 & 519 & 0.49 & 1.05 & \\
\hline $4 a$ & TBT $(0.1)$ & 543 & 2.07 & 419,586 & 429,595 & 0.11 & 1.81 & \\
\hline $4 b$ & TBT $(0.5)$ & 459 & 2.04 & 416,603 & 422,605 & 0.07 & 0.84 & \\
\hline $4 c$ & $\mathrm{TBT}(1)$ & 544 & 2.00 & 415,611 & 416,610 & 0.06 & 0.62 & 1.82 \\
\hline $4 \mathrm{~d}$ & TBT (2) & 540 & 1.98 & 621 & 416,612 & 0.04 & 0.40 & \\
\hline $4 \mathrm{e}$ & ТВТ (3) & 287 & 1.97 & 626 & 413,613 & 0.03 & 0.29 & \\
\hline $4 \mathrm{f}$ & TBT (5) & 459 & 1.95 & 630 & 415,621 & 0.03 & 0.20 & \\
\hline $5 a$ & PDI (0.1) & 693 & 1.96 & 450,590 & 440 & 0.07 & & \\
\hline $5 b$ & PDI (0.5) & 650 & 1.94 & 424,618 & 424 & 0.042 & 2.02 & \\
\hline $5 c$ & PDI (1) & 637 & 1.90 & 451,633 & 421,613 & 0.041 & 1.22 & 1.29 \\
\hline $5 d$ & PDI (2) & 656 & 1.88 & 641 & 417,627 & 0.037 & 0.96 & \\
\hline $5 e$ & PDI (3) & 583 & 1.87 & 649 & 408,630 & 0.036 & 0.27 & \\
\hline $5 f$ & PDI (5) & 563 & 1.85 & 655 & 414,636 & 0.026 & 0.49 & \\
\hline LP0 & & & 2.81 & 450 & 453 & & & 0.43 \\
\hline LP3 & BT (1) & & 2.38 & 522 & 398,520 & 0.43 & 4.37 & 0.94 \\
\hline LP4 & TBT (1) & & 1.90 & 448,624 & 400,612 & 0.14 & 1.14 & 0.15 \\
\hline LP5 & PDI (1) & & 1.85 & 447,643 & 400,638 & 0.13 & 0.33 & 0.56 \\
\hline
\end{tabular}

${ }^{a}$ Calculated from the onset of the absorption spectrum in solid state. ${ }^{b}$ The absolute quantum yields were estimated using Wrighton-GinleyMorse's method. ${ }^{30}$
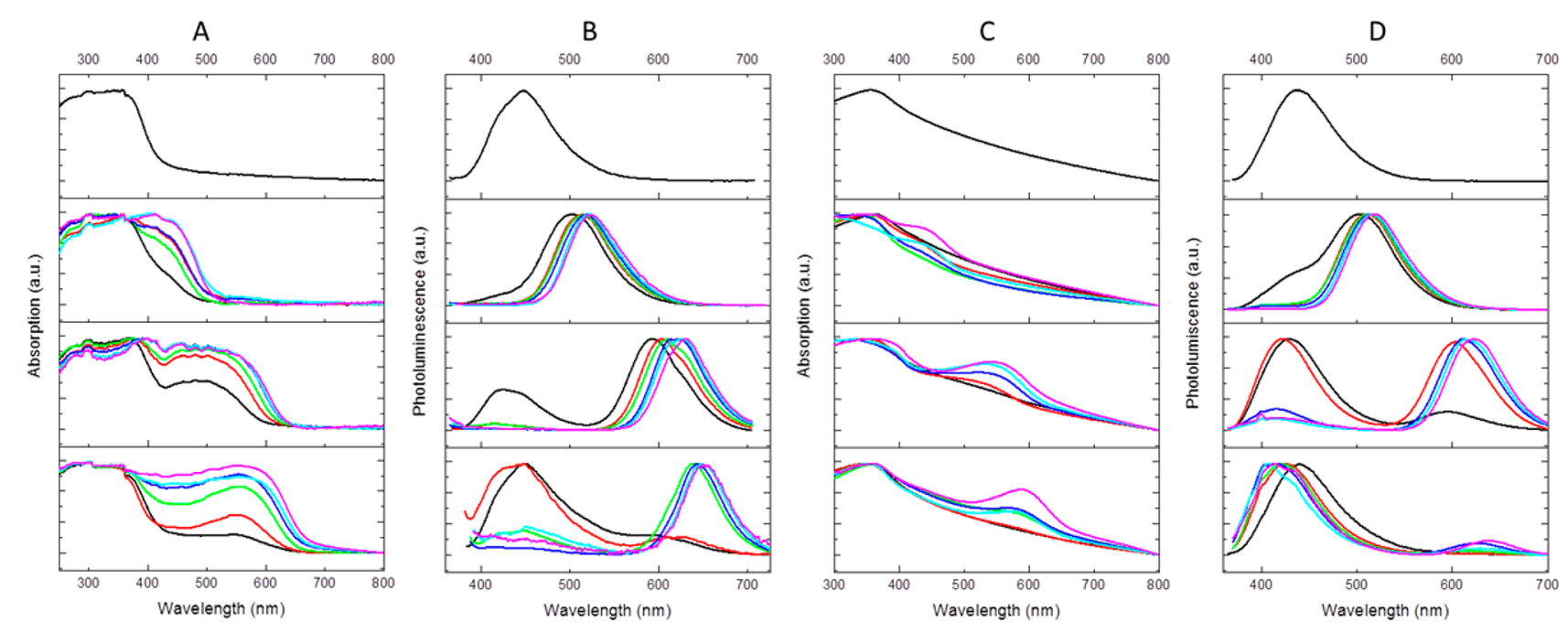

Figure 1. (A) Absorption and (B) photoluminescence spectra of CP-CMP0, CP-CMP3a-f, CP-CMP4a-f, and CP-CMP5a-f (from top to bottom) in the solid state; $(C, D)$ equivalent spectra in PEG dispersion, $\lambda_{\text {exc }}=360 \mathrm{~nm}$.

\section{RESULTS AND DISCUSSION}

Using the reaction conditions outlined in the Scheme 1, CPCMP0 was obtained as insoluble solid with a BrunauerEmmett-Teller surface area, $\mathrm{SA}_{\mathrm{BET}}$, of around $660 \mathrm{~m}^{2} \mathrm{~g}^{-1}$. CPCMP0 has a fluorescent emission centered at $445 \mathrm{~nm}$ when measured in the solid state, and at $436 \mathrm{~nm}$ when measured as a dispersion in polyethylene glycol 400 (PEG). This red shift of the emission from dispersion to solid state might be explained by the effect of aggregation of the polymer in the solid state compared with dispersion. ${ }^{29}$ The optical gap for CP-CMP0 was
$2.95 \mathrm{eV}$, as calculated from the onset of the absorption spectrum in solid state.

We first decided to tune the optical gap and photoluminescence in CP-CMP0 by adding an acceptor comonomer into the network. When a small amount $(0.1-5 \mathrm{~mol} \%)$ of dibromobenzo[c]-1,2,5-thiadiazole 3 (BT) was added to the reaction mixture, an insoluble green powder was obtained in all cases (CMP3a-f; Table 1). All of these doped polymers were found to be porous to nitrogen with surface areas comparable to the native polymer CP-CMPO $\left(\mathrm{SA}_{\mathrm{BET}}=306-731 \mathrm{~m}^{2} \mathrm{~g}^{-1}\right.$; Figure S1). Hence, introduction of the BT acceptor 
comonomer does not eliminate the microporosity in the networks, at least up to $5 \mathrm{~mol} \%$ levels. The absorbance spectra in the solid state, as measured in reflectance mode, show an extra peak for these BT-containing networks that is not present in CP-CMP0. The relative intensity of this secondary peak increases with the amount of BT introduced in the polymer (Figure 1A; second row). This second peak produces a redshift in the absorption onset, driving the calculated optical gap from $2.95 \mathrm{eV}$ for CP-CMP0 to $2.59 \mathrm{eV}$ for CP-CMP3a, and in gradual increments (CP-CMP3b-e) through to $2.41 \mathrm{eV}$ for CPCMP 3f. This shows that it is possible to fine-tune the optical gap by about $0.50 \mathrm{eV}$ by controlling the feed ratio of the acceptor comonomer, BT. Similar trends were found for the photoluminescence of these BT copolymers; CP-CMP3a-f all showed a green fluorescence in the solid state centered at 506 $\mathrm{nm}$ for CP-CMP3a that was red-shifted to $524 \mathrm{~nm}$ for CP-CMP 3f (Figure 2). The fluorescence of these polymers as dispersions in PEG showed a similar trend (Figure 2, lower).

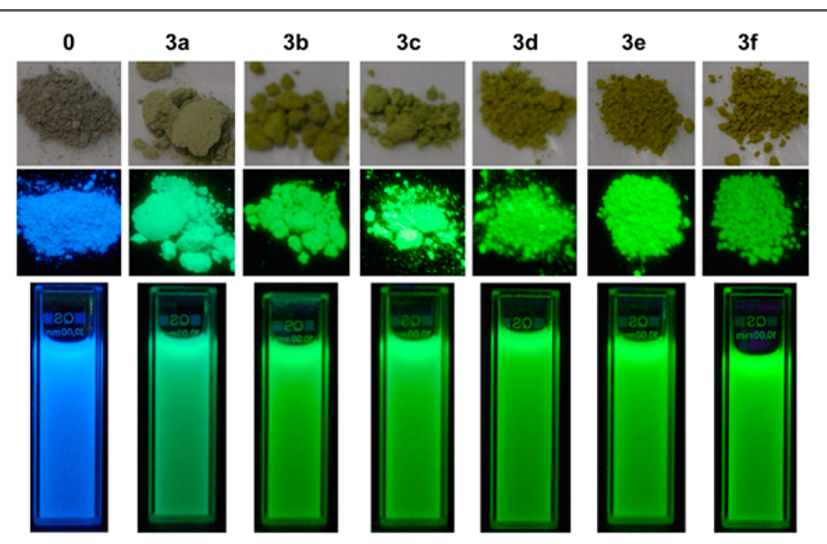

Figure 2. Photographs of CP-CMP0 and CP-CMP3a-f as powders and as dispersions in PEG under ambient light and under UV light (365 $\mathrm{nm})$.

A slight blueshift in emission was noted with respect to the solid state (Table 1). Dispersion of CP-CMP3a in PEG also led to a small shoulder around $430 \mathrm{~nm}$, attributed to the fluorescence of the polyphenylene framework. The amplification of the fluorescence due to the BT unit was calculated, both in the solid state and in dispersion. This amplification was calculated as the ratio of the emission of the polymer excited at the excitation maximum for the polyphenylene network, CPCMP0 (around $350 \mathrm{~nm}, I_{\mathrm{AD}}$ ) to the emission for the polymer excited at the excitation maximum of the BT unit (around 440 $\left.\mathrm{nm}, I_{\mathrm{A}}\right)$. In the solid state, the amplification was 0.92 for CPCMP3a and decreased in the series with the molar percentage of the BT. By contrast, the amplification in dispersion for CPCMP3a was higher (6.42), and but this value also decreased with the amount of BT in the polymer. We speculate that this difference is caused by the aggregation of the network in solid state, which leads to nonradiative decay of the exciton instead of the energy transfer to the BT unit in the polymer. In dispersion, this aggregation is lessened to a certain extent, and the exciton mobility allows the energy transfer from the polyphenylene framework to the BT unit, resulting in higher fluorescence amplification. ${ }^{31-34}$ The excitation spectra of the polymers dispersed in PEG show that the major contribution to the light absorption is due to the polyphenylene network, and an intense peak at around $350 \mathrm{~nm}$ is observed in all materials in the series (Figure S8). This suggests that the phenylene domain acts as an antenna, absorbing light before then transferring energy to the comonomer domain, where it is release as fluorescence. Although much higher amplification of emission has been reported in linear conjugated polymers, ${ }^{35}$ these values relate in most cases to soluble polymers, where aggregation can be avoided. This is impossible with these insoluble networks, although the inherent porosity avoids interchain aggregation to some degree, even in the solid state. ${ }^{20}$

Scheme 2. Synthesis of Linear Control Polymers, LPs

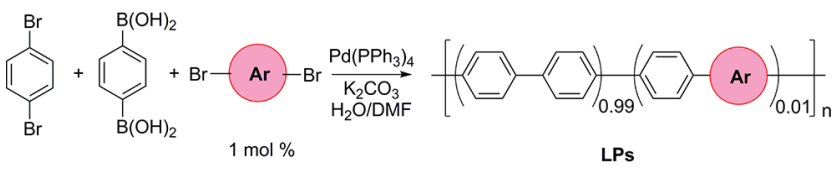

To illustrate the importance of microporosity in these CPCMPs, an analogous set of linear, nonporous polymers were synthesized using analogous reaction conditions used to produce the porous CP-CMPs (Scheme 2; LP0, LP3, LP4 and LP5, Table 1).

LP3, for example, incorporated $1 \mathrm{~mol} \%$ on the BT comonomer. Figure 3 (second row) shows the absorbance

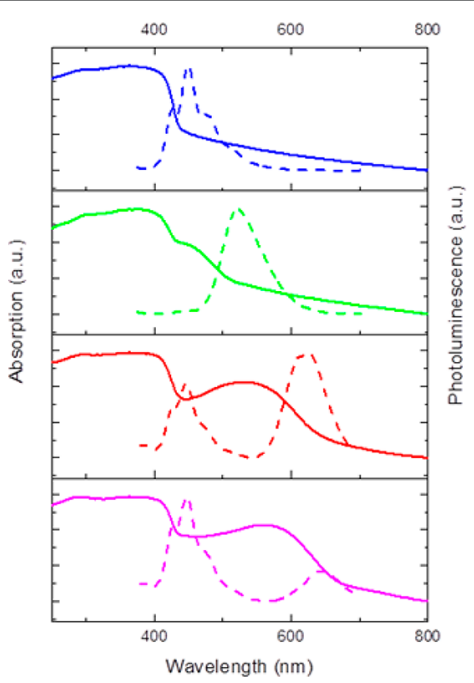

Figure 3. Solid-state absorption and photoluminescence $\left(\lambda_{\text {exc }}=360\right.$ $\mathrm{nm}$ ) of linear polymers LP0, LP3, LP4, and LP5 (from top to bottom).

and fluorescence spectra for linear LP3, measured as a solid powder, as compared to pure linear poly( $p$-phenylene), LP0 (top row). As for the porous copolymers, CP-CMP3a-f, the band gap and fluorescence in LP3 is tuned with the introduction of the BT comonomer. However, the fluorescence quantum yields for the porous and nonporous polymers were found to be quite different. The absolute fluorescence quantum yield (QY) in the solid state for CP-CMP3c ( $1 \mathrm{~mol} \% \mathrm{BT})$ was $7.1 \%$ compared with just $0.94 \%$ for the nonporous linear control polymer, LP3. More generally, and for two other comonomers discussed below, the QYs for porous CMPs were found to be about 1 order of magnitude higher than the corresponding nonporous linear copolymers (Table 1; see also CP-CMP4c vs LP4; CMP-CMP5c vs LP5). This can be explained by the inefficient monomer packing in CMPs, which avoids quenching in the solid state with respect to the nonporous linear polymers. 
We next extended this method to another comonomer, bis(2-bromo-5-thienyl)-2,1,3-benzothiadiazole (TBT, 4). Using a similar method, we introduced $0.1-5 \mathrm{~mol} \%$ TBT into the network, yielding insoluble powders that ranged in color from pale to deep red (Figure 3). These polymers were microporous (Figure S2) and had a surface area, $\mathrm{SA}_{\mathrm{BET}}$, ranging from 287 to $544 \mathrm{~m}^{2} \mathrm{~g}^{-1}$ (Table 1).

The TBT comonomer produced a red shift in the absorbance onset, tuning the band gap from $2.95 \mathrm{eV}$ (CP-CMP0) to around $2.0 \mathrm{eV}(2.07-1.95 \mathrm{eV}$, depending on the feed ratio of TBT comonomer). In the solid state, polymers CP-CMP4a-f show emission from pale orange for CP-CMP4a to deep red for CP-CMP 4f (Figure 4). Figure 1 (second row) shows the

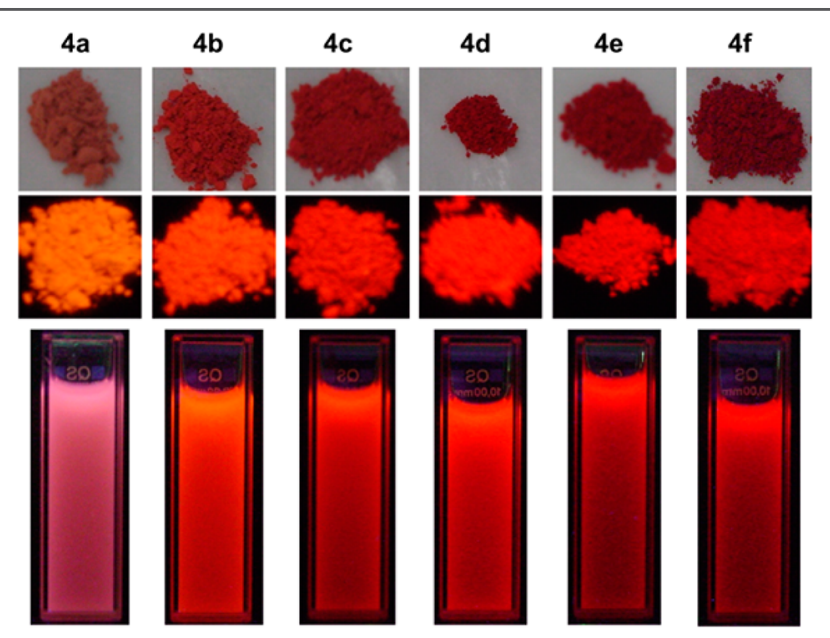

Figure 4. Photographs of CP-CMP4a-f as powders and as dispersions in PEG under ambient light and under UV light $(365 \mathrm{~nm})$.

photoluminescence spectra of CP-CMP4a-f, measured as powder and excited at $360 \mathrm{~nm}$. In contrast with CP-CMP 3s, CP-CMP4a-c shows a peak at around $417 \mathrm{~nm}$ due to the emission from the polyphenylene domain. A second peak in the emission spectra appears at around $600 \mathrm{~nm}$, assigned to the TBT unit. This peak experiences a red shift, increasing with the amount of the TBT in the network. The presence of the peak at around $420 \mathrm{~nm}$ in CP-CMP4a-f and the excitation spectra at the emission of the TBT unit $(600 \mathrm{~nm})$ points to energy transfer being less efficient than in the case of BT. When the emission of the polymers was recorded for dispersions in PEG, luminescence from pale pink to deep red was observed. In dispersion, CP-CMP4a shows a main peak at $429 \mathrm{~nm}$, and a second peak at $595 \mathrm{~nm}$. The relative intensity of these peaks swaps from CP-CMP4a to CP-CMP 4f. In the case of TBT, solid-state amplification of the emission for CP-CMP4a (0.1\% TBT) was less than one, showing a lack of energy transfer from the polyphenylene framework to the TBT unit. In dispersion, this amplification is higher (from 1.81 compared to 0.11 ), but still lower than for CP-CMP3a. Again, the nonporous linear control polymer, LP4, showed much lower fluorescence quantum yield than porous CP-CMP4c (0.15 vs $1.82 \%)$. For LP4 (and LP5, below), peaks from the emission of the phenylene units also appeared in the fluorescence spectra, possibly because of the low molecular weight of the unsubstituted linear polymers prepared under these polymerization reaction conditions. In this regard, the CP-CMPs are different from the linear polymers; these branched networks contain a multitude of end groups, which could be available for further reaction even after network precipitation. ${ }^{36}$ By contrast, the linear control polymers have just two end groups per polymer chain.

We also evaluated a mixture of 1,6- and 1,7-dibromoperylenediimide 5 (PDI; 1,6-: 1,7-isomer ratio 1:3) as comonomer in these networks. Again, we obtained porous, insoluble powders with surface areas, $\mathrm{SA}_{\mathrm{BET}}$, ranging from 563 to 693 $\mathrm{m}^{2} \mathrm{~g}^{-1}$ (Figure S3). The color of the resulting polymer goes from pale gray for CP-CMP5a to deep purple for CP-CMP $5 f$ (Figure S82). The emission spectra in the solid state show a main peak at $450 \mathrm{~nm}$ and second peak at around $600 \mathrm{~nm}$. Emission spectra for the CP-CMP5a-f series as dispersions in PEG show a peak at $440 \mathrm{~nm}$, and a second peak appears around $610 \mathrm{~nm}$, the intensity of which increases with the amount of PDI in the network. CP-CMP $5 f$ has just a single emission peak at $655 \mathrm{~nm}$. Like the TBT networks, CP-CMP5a-f show little amplification of the emission in the solid state, indicating that the energy transfer for the PDI unit in this network is again less effective than for BT.

The observed energy transfer processes could in principle occur within an individual polymer particle or between two separate polymer particles. To test this, polymers CP-CMP0, CP-CMP $3 f$ and CP-CMP $4 \mathrm{f}$ were mixed both as dispersions in PEG and in the solid state. These physical mixtures were then analyzed by absorption and photoluminescence spectroscopy. For experiments using dispersions, a dispersion of one of the chosen polymers was added to a dispersion of second polymer, and the fluorescence was measured after every addition. In all of the combinations of these experiments, the intensity of the peak due to the first polymer did not change drastically after several additions of the second; this suggests that no substantial energy transfer takes place between polymer particles in physical mixtures of PEG dispersions (Figure S20). Likewise, when these mixing experiments were carried out in the solid state, the photoluminescence spectra and the absorption spectra were the sum of the spectra of the component polymers (Figure S21).

These experiments showed that energy is not transferred between particles, at least for physical mixtures prepared after polymerization. However, it is likely that individual polymer particles can become entangled during synthesis, as suggested by SEM images for these polymers (Figure S79). In this situation, energy could transfer between fused particles, and it is conceivable that phase-separated domains might occur, for example if one monomer is much more reactive than another. To better understand the energy transfer mechanisms in these polymers, we prepared three model compounds $(6,7$, and 8 ) using standard Suzuki-Miyaura coupling (Figure 5 and the Supporting Information).

Figure 5 shows the excitation and emission spectra of CPCMP0 and the three model compounds, either in dispersion or in solution in PEG. The overlap of the emission of CP-CMP0 with the excitation spectrum of $\mathbf{6}$ is clearly bigger than for either 7 or 8 , and this explains the more efficient energy transfer in the networks CP-CMP3a-f. The smaller difference between the CP-CMP4 and CP-CMP5 series is not explained by the excitation spectra of 7 and 8 , but this could be due to the different dipole moment in the PDI unit compare to TBT, and also a degree of fluorescence quenching by the PDI unit taking place in the electron transfer processes. ${ }^{37,38}$

The emission tuning described above suggested the possibility of obtaining white emitting CMP by combining blue, green and red fluorescence (Figures 2 and 4) in a single material. Single-component white emitting materials are 


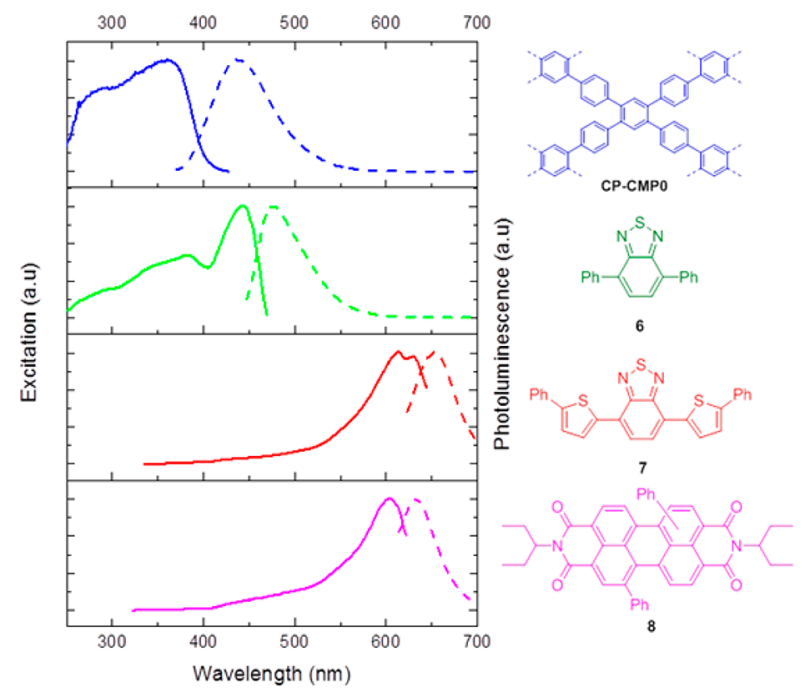

Figure 5. Excitation and photoluminescence spectra of CP-CMP0, and model compounds 6, 7, and 8 in PEG (from top to bottom).

interesting in the development of white LEDs that avoid the phase segregation often generated by aging in multiple component LEDs. ${ }^{39}$ Moreover, the inherent porosity in CMPs might in principle help to avoid quenching. To the best of our knowledge, only two examples are reported for white-emitting CMPs, ${ }^{40,41}$ but in both cases, a dye is loaded into the porous network to obtain white emission via a combination of CMP and dye emissions. We decided to introduce two comonomers (BT and TBT) into the same polymer in order to provide the green and red emission, respectively, along with the blue fluorescence from the native polyphenylene network (Scheme 3).

\section{Scheme 3. Synthesis of White Emitting CP-CMPws}

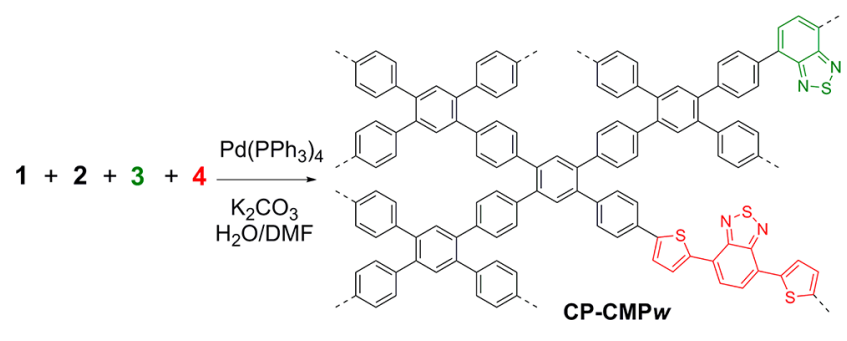

This approach has been used in dendrimers ${ }^{42,43}$ and in hyperbranched polymers, ${ }^{44,45}$ to obtain nonporous white emitting materials. We prepared a library of $25 \mathrm{CP}-\mathrm{CMPs}$ where the feed ratio of acceptors BT and TBT were systematically modified toward a whiter fluorescence. Table S1 shows the library of $25 \mathrm{CP}$-CMPs prepared by incorporating the two comonomers in different feed ratios. Figures S22-S26 show the absorbance and emission spectra of all of these polymers as measured in the solid state and as dispersions in PEG; these data show that fine-tuning of the fluorescence could be achieved (Figure S83). Absorbance and emission of these polymers differ strongly when they were measured as solids or as PEG dispersions, probably due to emission-reabsorption and aggregation processes in solid state. Figure S25 shows emission spectra for CP-CMPws, where, notably, the major contribution to the fluorescence is due to the polyphenylene domain. Also, a quenching of the emission of the BT unit is induced when TBT is also incorporated in the network, in comparison to the emission spectrum observed for CP-CMP 3s (Figure 1). This is probably due to the transfer of energy from the phenylene network to the BT unit, and from the BT unit to TBT unit.

After an extensive search, we were able to identify CPCMPw11, which contained BT and TBT in the feed ratio 0.028 TBT: 0.1 BT. In PEG dispersions, excitation at $365 \mathrm{~nm}$ provides a close-to "white" emission (Figure 6). The emission

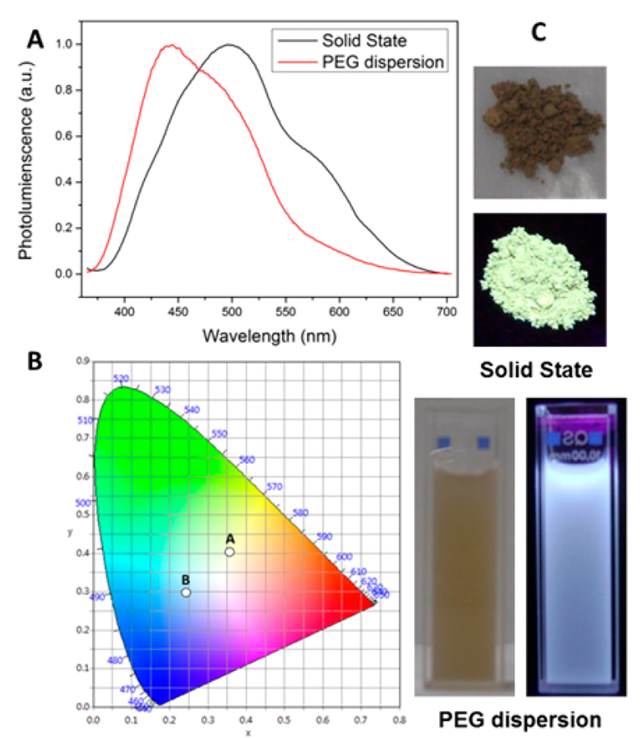

Figure 6. (A) Photoluminescence $\left(\lambda_{\text {exc }}=360 \mathrm{~nm}\right)$ of CP-CMPw11 in solid state and as a PEG dispersion. (B) CIE chromatograph of $(x, y)$ coordinates for CP-CMPw11 emission in (A) the solid state and (B) in PEG dispersion. (C) Photographs of solid and dispersed sample CP-CMPw11 under ambient light and under UV light $(365 \mathrm{~nm})$.

spectra of this dispersion excited at $360 \mathrm{~nm}$ gave a CIE coordinates $(0.25,0.30) .{ }^{46}$ In the solid state, this polymer shows a fluorescence quantum yield of $8.8 \%$, slightly higher than reported previously for dye-loaded CMP. ${ }^{40}$ As discussed above, the intrinsic microporosity of this copolymer network reduces the level of aggregation, thus allowing a relatively high quantum yield $\left(\mathrm{SA}_{\mathrm{BET}}=580 \mathrm{~m}^{2} \mathrm{~g}^{-1}\right.$; Figure $\left.\mathrm{S} 4\right)$. When a similar feed ratio of $\mathbf{3}$ and $\mathbf{4}$ was used in analogous nonporous linear polymers, a green emission was observed instead of white emission (Figures S27 and S28). This may be due to the low molecular weight of the linear polymers, which could prevent the inclusion of two different acceptors in the same linear chain.

We next considered the possibility of deliberately forming porous networks comprising separated domains that contain just one of the acceptor comonomers. This was inspired by the quenching of fluorescence of BT by TBT in CMPws when the comonomers are mixed homogeneously in the network, and also by the fact that BT extinguishes the fluorescence of polyphenylene at a feed ratio of over $0.5 \mathrm{~mol} \%$. To avoid these effects, we decided to prepare the same type of CMPs but under reaction conditions that might generate separate domains, with the intention of physically isolating the acceptor comonomers. Specifically, we used more diluted synthesis conditions in order to avoid the rapid precipitation of the polymer networks, and to keep any phase-separated material dispersed in the reaction medium. First, we synthesized the parent polyphenylene, CP-CMP01, which is analogous to CPCMP0, under these new reaction conditions. The resulting material has similar photophysical properties to CP-CMP0, 
with an emission peak at $457 \mathrm{~nm}$ in the solid state and at 451 in PEG dispersion. Also, CP-CMP01 retains a microporous structure, with a BET surface area of $956 \mathrm{~m}^{2} \mathrm{~g}^{-1}$. Then our aim was to study the effect of the monomer addition sequence on the photophysical properties of the resulting materials. We hence prepared polymers CP-CMP-acceptor $(\%)_{\text {domain }}$ with three different domain structures (Scheme 4, Table 2).

Scheme 4. Domain Formation in CMPs with One Accceptor by Monomer Addition Sequence Paths

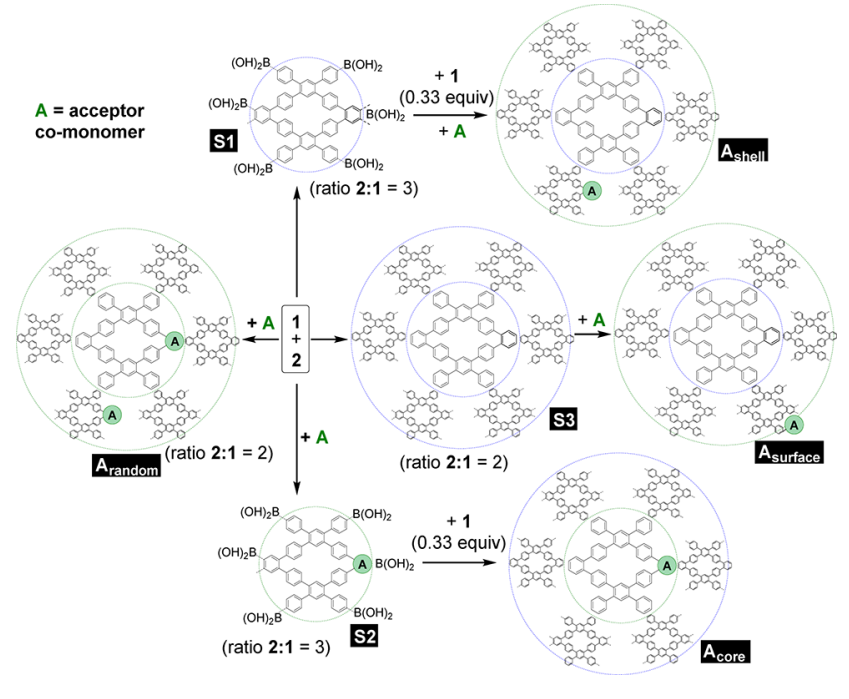

Table 2. Acceptor Feed Ratio, Addition Sequence, Fluorescence, and Emission Amplification of CP-CMP Polymers Containing a Single Acceptor Co-monomer

\begin{tabular}{|c|c|c|c|c|}
\hline $\begin{array}{c}\text { polymer CP-CMP } \\
\text { (acceptor } \\
\left.(\text { mol \% })_{\text {domain }}\right)\end{array}$ & $\begin{array}{l}\lambda_{\text {emission }} \\
(\mathrm{nm}) \\
\text { solid } \\
\text { state }\end{array}$ & $\begin{array}{c}\lambda_{\text {emission }} \\
(\mathrm{nm}) \\
\text { dispersion } \\
\text { PEG }\end{array}$ & $\begin{array}{c}\text { amplification } \\
\text { solid state } \\
I_{\mathrm{AD}} / I_{\mathrm{A}}\end{array}$ & $\begin{array}{c}\text { amplification } \\
\text { dispersion } \\
\operatorname{PEG} I_{\mathrm{AD}} / I_{\mathrm{A}}\end{array}$ \\
\hline 01 & 457 & 451 & & \\
\hline $\mathrm{BT}(1 \%)_{\text {random }}$ & 521 & 514 & 0.39 & 11.7 \\
\hline $\mathrm{BT}(1 \%)_{\text {shell }}$ & 515 & 512 & 0.58 & 12.8 \\
\hline $\mathrm{BT}(1 \%)_{\text {core }}$ & 520 & 514 & 0.51 & 12.5 \\
\hline $\mathrm{BT}(1 \%)_{\text {surface }}$ & 517 & 515 & 0.49 & 18.8 \\
\hline $\operatorname{TBT}(1 \%)_{\text {random }}$ & 451,606 & 426,603 & 0.10 & 1.8 \\
\hline $\operatorname{TBT}(1 \%)_{\text {shell }}$ & 445,600 & 436,602 & 0.11 & 2.2 \\
\hline $\operatorname{TBT}(1 \%)_{\text {core }}$ & 449,605 & 427,608 & 0.09 & 3.4 \\
\hline $\operatorname{TBT}(1 \%)_{\text {surface }}$ & 451,594 & 442,600 & 0.13 & 0.4 \\
\hline $\mathrm{BT}(0.5 \%)_{\text {random }}$ & 513 & 508 & 0.57 & 13.5 \\
\hline $\mathrm{BT}(0.5 \%)_{\text {shell }}$ & 508 & 507 & 1.2 & 15.5 \\
\hline $\mathrm{BT}(0.5 \%)_{\text {core }}$ & 519 & 509 & 0.60 & 23.0 \\
\hline $\mathrm{BT}(0.5 \%)_{\text {surface }}$ & 510 & 451,502 & 0.92 & 17.6 \\
\hline $\operatorname{TBT}(0.5 \%)_{\text {random }}$ & 443,599 & 433,601 & 0.11 & 1.9 \\
\hline $\operatorname{TBT}(0.5 \%)_{\text {shell }}$ & 451,587 & 442,588 & 0.24 & 3.1 \\
\hline $\operatorname{TBT}(0.5 \%)_{\text {core }}$ & 451,602 & 434,601 & 0.11 & 2.5 \\
\hline $\operatorname{TBT}(0.5 \%)_{\text {surface }}$ & 446,580 & 435,583 & 0.26 & 3.9 \\
\hline $\mathrm{BT}(0.1 \%)_{\text {surface }}$ & 499 & 451 & 1.29 & \\
\hline $\mathrm{BT}(0.1 \%)_{\text {shell }}$ & 469 & 445 & 1.03 & \\
\hline
\end{tabular}

When a mixture 1 ( 1 equiv), 2 (2 equiv), and the corresponding acceptor (BT or TBT) in DMF was reacted together, a polymer is obtained where the acceptor is, ideally, distributed homogeneously throughout the network, as represented by $A_{\text {random. }}$ By contrast, when a mixture of 1 (1 equiv) and 2 ( 3 equiv) is heated at $90{ }^{\circ} \mathrm{C}$ for $20 \mathrm{~h}$, this results in a polymeric structure with an excess of boronic acid functionalities as end-groups (S1).

This first stage product, $S 1$, was then reacted with an additional 0.33 equiv of 1 and the acceptor comonomer at 120 ${ }^{\circ} \mathrm{C}$ for 2 days, thus yielding $\mathrm{A}_{\text {shell }}$ where the acceptor comonomer is, ideally, located mainly in the nominal "shell" of the polymer particles. ${ }^{47}$ Swapping the order of addition of the acceptor yields $A_{\text {core }}$, where the acceptor is, in an idealized scheme, in the nominal "core" of the particles. This latter strategy was already reported by others, ${ }^{48}$ and the authors of that work claimed core-shell polymer particles. We also attempted to form structure $A_{\text {surface, }}$ where the initial mixture of 1 ( 1 equiv) and 2 ( 2 equiv) was heated at $120{ }^{\circ} \mathrm{C}$ for $24 \mathrm{~h}$, followed by addition of the acceptor comonomer when the other two monomers are almost consumed, thus biasing the acceptor to react at the surface of the polymer particle. Polymers BT $(1 \%)_{\text {random, core, shell, and surface have the same feed }}$ ratio of BT ( $1 \mathrm{~mol} \%)$ with respect to 1 and 2 , but differ only in the addition sequence. The absorption spectra of these four polymers look similar as powders and as dispersions in PEG (Figures S29 and S30). The emission spectra for powder samples are also similar to one another (Figure S29), but slight differences can be observed in the emission spectra for the polymers dispersed in PEG (Figure 7A). The emission spectra
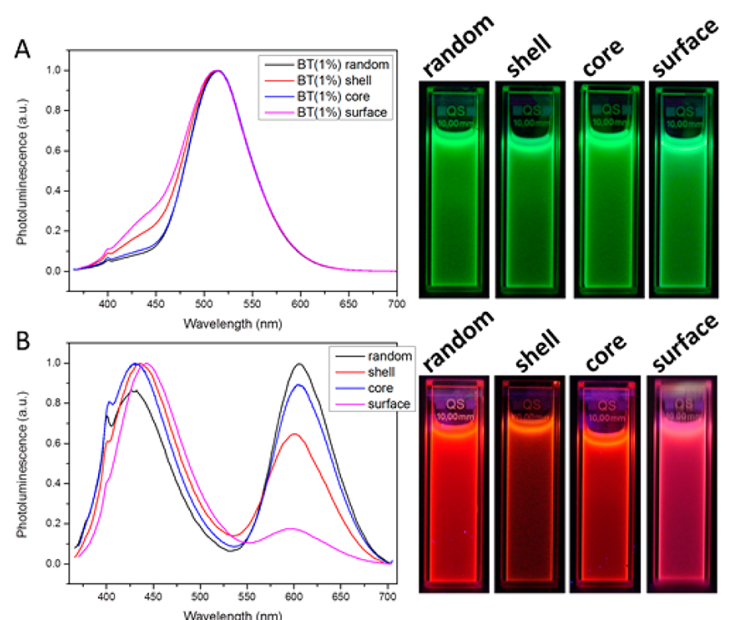

Figure 7. Photoluminescence of PEG dispersions of polymers (A) CP-

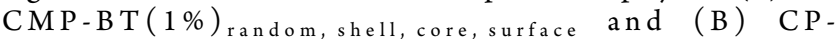
$\operatorname{CMPTBT}(1 \%)_{\text {random, shell, core, surface }}\left(\lambda_{\text {exc }}=360 \mathrm{~nm}\right)$ and photographs of PEG dispersions under UV light $(365 \mathrm{~nm})$.

of $\mathrm{BT}(1 \%)_{\text {random }}$ and $\mathrm{BT}(1 \%)_{\text {core }}$ show a peak only at around $510 \mathrm{~nm}$, but in case of BT $(1 \%)_{\text {shell }}$ and BT $(1 \%)_{\text {surface, }}$ a second shoulder peak at $430 \mathrm{~nm}$ appears, probably due to the emission of the polyphenylene units. This suggests that the energy transfer from the polyphenylene framework to the acceptor, $\mathrm{BT}$, is less efficient in structures $A_{\text {shell }}$ and $A_{\text {surface }}$ than in structures $A_{\text {random }}$ and $A_{\text {core }}$. This is consistent with the energy transfer being distance dependent.

In case of using TBT in a $1 \mathrm{~mol} \%$ feed ratio, we obtained

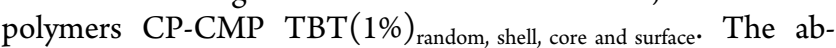
sorption spectra of these polymers measured as powder or as dispersion in PEG look similar (Figure S31 and 32). Solid-state emission of polymers $\mathrm{TBT}(1 \%)_{\text {random, }} \mathrm{TBT}(1 \%)_{\text {shell }}$ and $\mathrm{TBT}(1 \%)_{\text {core }}$ show and main peak at $600 \mathrm{~nm}$, but polymer TBT $(1 \%)_{\text {surface }}$ shows a peak at $451 \mathrm{~nm}$ (Figure S31). Emission spectra of these polymers measured as dispersion (Figure 7B) 
Table 3. Acceptor Feed Ratio, Addition Sequence, Fluorescence, and Emission Amplification of Polymers CP-CMPs ${ }^{a}$

\begin{tabular}{|c|c|c|c|c|}
\hline $\begin{array}{c}\text { polymer CP-CMP }\left(\text { acceptor }(\mathrm{mol} \%)_{\text {domain }} \text { acceptor }\right. \\
\left.(\text { mol \% })_{\text {domain }}\right)\end{array}$ & $\begin{array}{l}\lambda_{\text {emission }}(\mathrm{nm}) \text { solid } \\
\text { state }\end{array}$ & $\begin{array}{c}\lambda_{\text {emission }}(\mathrm{nm}) \text { dispersion } \\
\text { PEG }\end{array}$ & $\begin{array}{l}\text { amplification solid state } \\
\qquad I_{\mathrm{AD}} / I_{\mathrm{A}}\end{array}$ & $\begin{array}{l}\text { amplification dispersion PEG } \\
\qquad I_{\mathrm{AD}} / I_{\mathrm{A}}\end{array}$ \\
\hline $\mathrm{BT}(1 \%)_{\text {random }} \mathrm{TBT}(1 \%)_{\text {random }}$ & 469,606 & $429,500,607$ & 0.10 & $9.06,1.94$ \\
\hline $\mathrm{BT}(1 \%)_{\text {core }} \mathrm{TBT}(1 \%)_{\text {shell }}$ & $470(w), 601$ & 431, 491, 599 & 0.12 & $10.2,2.84$ \\
\hline $\operatorname{TBT}(1 \%)_{\text {core }} \mathrm{BT}(1 \%)_{\text {shell }}$ & $470(w), 606$ & 431, 495(w), 604 & 0.08 & $11.36,1.85$ \\
\hline $\mathrm{BT}(1 \%)_{\text {random }} \mathrm{TBT}(1 \%)_{\text {surface }}$ & 520,581 & $430,511,580$ & $0.64,0.35$ & $13.55,3.18$ \\
\hline $\mathrm{TBT}(1 \%)_{\text {random }} \mathrm{BT}(1 \%)_{\text {surface }}$ & 455(w), 603 & 430,600 & 0.09 & 1.39 \\
\hline $\mathrm{BT}(1 \%)_{\text {core }} \mathrm{TBT}(1 \%)_{\text {surface }}$ & 523,568 & $510(\mathrm{~b})$ & $0.57,0.75$ & 13.0 \\
\hline $\mathrm{TBT}(1 \%)_{\text {core }} \mathrm{BT}(1 \%)_{\text {surface }}$ & 449,606 & 435,606 & 0.12 & 1.75 \\
\hline $\mathrm{BT}(0.5 \%)_{\text {random }} \mathrm{TBT}(0.5 \%)_{\text {random }}$ & 451(w), 602 & $440,500,602$ & 0.11 & $15.4,2.4$ \\
\hline $\mathrm{BT}(0.5 \%)_{\text {core }} \mathrm{TBT}(0.5 \%)_{\text {shell }}$ & $500(\mathrm{w}), 594$ & $431,506,596$ & 0.11 & $13.4,2.3$ \\
\hline $\operatorname{TBT}(0.5 \%)_{\text {core }} \mathrm{BT}(0.5 \%)_{\text {shell }}$ & 594 & $431,504,593$ & 0.12 & $16.1,3.0$ \\
\hline $\operatorname{BT}(0.5 \%)_{\text {random }} \mathrm{TBT}(0.5 \%)_{\text {surface }}$ & $515,600(\mathrm{~s})$ & $510,600(s)$ & $0.55,0.31$ & $18.0,2.8$ \\
\hline $\mathrm{TBT}(0.5 \%)_{\text {random }} \mathrm{BT}(0.5 \%)_{\text {surface }}$ & 453(w), 599 & 437,602 & 0.14 & 2.6 \\
\hline $\mathrm{BT}(0.5 \%)_{\text {core }} \mathrm{TBT}(0.5 \%)_{\text {surface }}$ & 515 & $430(s), 505$ & 0.67 & 24.8 \\
\hline $\operatorname{TBT}(0.5 \%)_{\text {core }} \mathrm{BT}(0.5 \%)_{\text {surface }}$ & $452(w), 602$ & 430,604 & 0.15 & 2.2 \\
\hline $\mathrm{BT}(0.1 \%)_{\text {random }} \mathrm{TBT}(0.1 \%)_{\text {random }}$ & 493,586 & $433,490(s), 584$ & $0.91,0.26$ & $19.6,3.2$ \\
\hline $\mathrm{BT}(0.1 \%)_{\text {core }} \mathrm{TBT}(0.1 \%)_{\text {shell }}$ & 475,585 & $444,500(s), 590$ & $0.83,0.14$ & $33.3,4.0$ \\
\hline $\operatorname{TBT}(0.1 \%)_{\text {core }} \mathrm{BT}(0.1 \%)_{\text {shell }}$ & 470,580 & $444,500(s), 590$ & $1.07,0.20$ &,- 2.8 \\
\hline $\mathrm{BT}(0.1 \%)_{\text {random }} \mathrm{TBT}(0.1 \%)_{\text {surface }}$ & $501,560(s)$ & $485(b)$ & $0.98,0.47$ & $51.5,3.8$ \\
\hline $\operatorname{TBT}(0.1 \%)_{\text {random }} \mathrm{BT}(0.1 \%)_{\text {surface }}$ & 454,588 & 440,591 & 0.25 & 3.1 \\
\hline $\mathrm{BT}(0.5 \%)_{\text {core }} \mathrm{TBT}(0.1 \%)_{\text {shell }}$ & 517,574 & $432(\mathrm{~s}), 509,590(\mathrm{~s})$ & $0.61,0.36$ & $22.8,2.7$ \\
\hline $\mathrm{BT}(0.5 \%)_{\text {random }} \mathrm{TBT}(0.1 \%)_{\text {surface }}$ & 519 & $430(s), 507$ & 0.60 & 21.8 \\
\hline $\mathrm{BT}(1 \%)_{\text {core }} \mathrm{TBT}(0.5 \%)_{\text {surface }}$ & 523 & $420(s), 514$ & 0.65 & 19.1 \\
\hline
\end{tabular}

have two peaks (430 and $600 \mathrm{~nm}$ ), and interestingly the relative intensity of the peak at $600 \mathrm{~nm}$ decreased in the order $\operatorname{TBT}(1 \%)_{\text {random }}-$ TBT $(1 \%)_{\text {core }}-\mathrm{TBT}(1 \%)_{\text {shell }}$ TBT $(1 \%)_{\text {surface }}$. The efficiency of the energy transfer in these systems follows the trend $A_{\text {random }}>A_{\text {core }}>A_{\text {shell }}>A_{\text {surface, }}$ this agrees with the aforementioned distance dependence. Nevertheless, in structures $A_{\text {shell }}$ and $A_{\text {surface, }}$ self-quench emission could take place because of a locally high concentration of acceptor units. Similar behavior was observed when using a $0.5 \mathrm{~mol} \%$ feed ratio of BT (Figures S33 and S34) or TBT (Figures S35 and S36).

Polymers CP-CMP-BT $(1 \%)_{\text {random, TBT }}(1 \%)_{\text {random }}$, $\mathrm{BT}(0.5 \%)_{\text {random, }}$ and $\mathrm{TBT}(0.5 \%)_{\text {random }}$ in PEG dispersion showed higher amplification of emission of the acceptor compare with their analogous polymers CP-CMP3c, 3b, 4c, and $4 \mathrm{~b}$, respectively. We postulate this is because the degree of interpenetration of the polymer chains in the network is lower than in the previous reaction conditions, allowing a higher degree of freedom to the polymer chains to swell in dispersion of PEG, decreasing the aggregation and permitting the mobility of the exciton through the network. This assumption is based on two facts; first, the amplification of the emission of the acceptor measured in the solid state is similar in polymers synthesized by two different conditions (Tables 1 and 2). Second, polymers $A_{\text {random, }}$ prepared using the less concentrated reaction conditions, show higher swelling behavior in contact with organic solvents. We prepared analogous polymer structure $A_{\text {shell }}$ and $A_{\text {surface }}$ using a two-steps synthesis. Initially, first stage polymers as S1 were isolated and purified, and then submitted to the second reaction step with 0.33 equiv of 1,1 equiv of 2 , and $1 \%$ of $\mathrm{BT}$ or TBT, respectively. The polymer with a structure $A_{\text {shell }}$ prepared in two steps fashion showed a different emission to the polymer prepared in one pot. Polymer $\mathrm{BT}(1 \%)_{\text {shell }}$ shows one peak at $514 \mathrm{~nm}$ in the emission spectra, but polymer $\mathrm{BT}(1 \%)_{\text {shell }}$ made in two steps shows two peaks in the emission (440 and $510 \mathrm{~nm}$ ) (Figure S48). Also, polymer $\operatorname{TBT}(1 \%)_{\text {shell }}$ (two step) show a relatively less intense fluorescence peak at $600 \mathrm{~nm}$ compared to the polymer $\mathrm{TBT}(1 \%)_{\text {shell }}$ in one pot (Figure S48). These differences are probably due to in the two-step synthesis, the resulting material is a physical mixture of two polymers, keeping their emission independently, in contrast with the one-pot synthesis. Also polymers structures similar to $\mathrm{A}_{\text {surface }}$ were prepared in a twostep fashion, just by isolation of the first-stage polymer S3, purification, and subsequent reaction with acceptor BT or TBT in $1 \mathrm{~mol} \%$ ratio. In these cases, although some differences are observed in emission of the polymers of polymer BT $(1 \%)_{\text {surface }}$ vs $\operatorname{BT}(1 \%)_{\text {surface }}$ (two step) and $\mathrm{TBT}(1 \%)_{\text {surface }}$ vs TBT $(1 \%)_{\text {surface }}$ (two step), similar emission spectra are obtained in both methods, pointing to a similar material in both approaches (Figures S49 and 50).

Next, we considered the introduction of two acceptors in different domains of the same polymer network, and studied the difference in the emission spectra (Table 3). To do so, we use a similar method to the above-mentioned and described in the Scheme 5. Polymer CP-CMP BT $(1 \%)_{\text {random }}$ TBT $(1 \%)_{\text {random }}$ contains both BT and TBT in $1 \mathrm{~mol} \%$ feed ratio; ideally, these monomers are homogeneously distributed through the polymer network. The inclusion of two acceptors in the polymer allowed us also to study the difference in the addition sequential, e.g., first BT and after TBT, and vice versa. Also, this two-acceptor study allowed the introduction of another domain structure, $A_{\text {core }} B_{\text {surface, }}$ where first a domain is grown containing one of the acceptors, followed by the growth of a second domain without acceptor (just polyphenylene), and then the addition of the second acceptor to react with the residual functional groups of the surface of the polymer network. The different distribution of the acceptor comonomers in the network leads to a different photoluminescence in the resulting material. For example, polymers CP-CMP BT(1\%)TBT(1\%)s have the same feed 
Scheme 5. Domain Formation in CMPs Containing Two Acceptors by Monomer Addition Sequence Paths

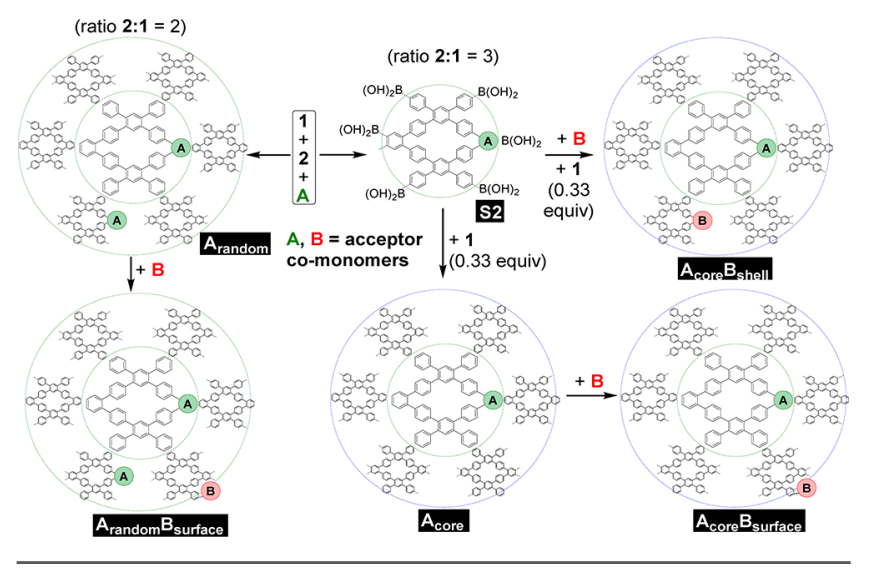

ratio BT ( $1 \mathrm{~mol} \%)$ and TBT ( $1 \mathrm{~mol} \%)$ but a different addition sequence. Photoluminescence measured as solid state of these polymers show similar shape for all except BT $(1 \%)_{\text {random }}$ TBT$(1 \%)_{\text {surface }}$ and $\mathrm{BT}(1 \%)_{\text {core }} \mathrm{TBT}(1 \%)_{\text {surface }}$. For polymers CPCMP BT $(1 \%)_{\text {random }} \mathrm{TBT}(1 \%)_{\text {random, }} \mathrm{BT}(1 \%)_{\text {core }} \mathrm{TBT}(1 \%)_{\text {shell }}$, $\operatorname{TBT}(1 \%)_{\text {core }} \mathrm{BT}(1 \%)_{\text {shell }}, \mathrm{TBT}(1 \%)_{\text {random }} \mathrm{BT}(1 \%)_{\text {surface, }}$ and $\mathrm{TBT}(1 \%)_{\text {core }} \mathrm{BT}(1 \%)_{\text {surface }}$, photoluminescence spectra in solid state show a main peak around $600 \mathrm{~nm}, \mathrm{BT}(1 \%)_{\text {random }}$ TBT$(1 \%)_{\text {surface }}$ shows two peaks around 520 and $581 \mathrm{~nm}$, and $\mathrm{BT}(1 \%)_{\text {core }} \mathrm{TBT}(1 \%)_{\text {surface }}$ a broad peak with shoulders at 523 and $568 \mathrm{~nm}$ (Figure S39). More differences are observed in the emission spectra of these materials when measured as dispersion in PEG (Figure 8). Random copolymer $\mathrm{BT}(1 \%)_{\text {random }} \mathrm{TBT}(1 \%)_{\text {random }}$ shows three peaks spectra (429, 500 , and $607 \mathrm{~nm}$ ) being 429 and $500 \mathrm{~nm}$ less intense than the one at $607 \mathrm{~nm}$. The relative intensity of the peaks changes depending of the addition sequence. For BT $(1 \%)_{\text {core }}$ TBT-

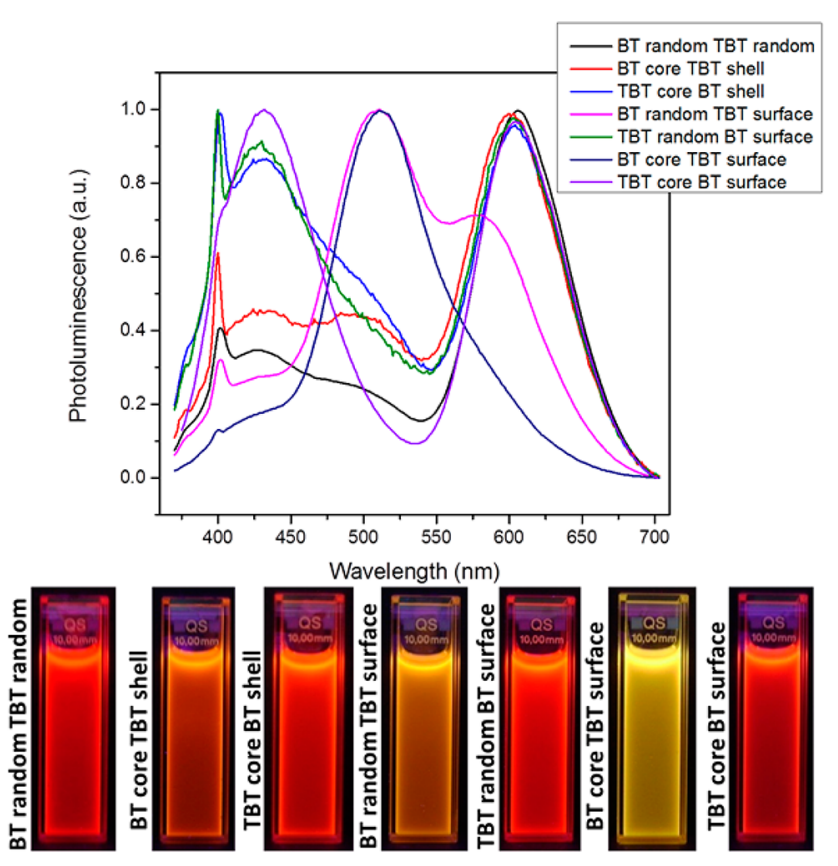

Figure 8. Photoluminescence of PEG dispersions of polymers CPCMP BT(1\%)TBT $(1 \%) \mathrm{s}\left(\lambda_{\text {exc }}=360 \mathrm{~nm}\right.$, Raman scatter peak from solvent at $400 \mathrm{~nm}$ ) and photographs of PEG dispersions under UV light $(365 \mathrm{~nm})$.
$(1 \%)_{\text {shell }}$ the intensity of the peaks at 430 and $491 \mathrm{~nm}$ increase respect to $\mathrm{BT}(1 \%)_{\text {random }} \mathrm{TBT}(1 \%)_{\text {random }}$. In $\mathrm{TBT}(1 \%)_{\text {core }} \mathrm{BT}$ $(1 \%)_{\text {shell }}$ emission spectra the contribution from BT emission is weaker and the spectrum shows a decrease in the intensity of the peak at $495 \mathrm{~nm}$. The fluorescence spectra for $\mathrm{BT}(1 \%)_{\text {random }} \mathrm{TBT}(1 \%)_{\text {surface }}$ has a main peak around $511 \mathrm{~nm}$, in contrast with $\mathrm{TBT}(1 \%)_{\text {random }} \mathrm{BT}(1 \%)_{\text {surface }}$ where that peak almost disappears. Photoluminescence spectra in PEG for $\mathrm{BT}(1 \%)_{\text {core }} \mathrm{TBT}(1 \%)_{\text {surface }}$ show a peak at $510 \mathrm{~nm}$ with a small shoulder around $600 \mathrm{~nm}$, and $\mathrm{TBT}(1 \%)_{\text {core }} \mathrm{BT}(1 \%)_{\text {surface }}$ has two peaks 435 and $606 \mathrm{~nm}$. Again, these differences can be understood based on the difference position of the acceptor in the network and the effect of the distance between donor polyphenylene unit and the corresponding acceptor. In polymers CP-CMPs BT $(1 \%)_{\text {random }} \mathrm{TBT}(1 \%)_{\text {random, }}$ BT$(1 \%)_{\text {core }} \mathrm{TBT}(1 \%)_{\text {shell }}, \mathrm{TBT}(1 \%)_{\text {core }} \mathrm{BT}(1 \%)_{\text {shell }}, \mathrm{TBT}(1 \%)_{\text {random }}$ $\mathrm{BT}(1 \%)_{\text {surface, }}$ and $\mathrm{TBT}(1 \%)_{\text {core }} \mathrm{BT}(1 \%)_{\text {surface, }}$ the presence of TBT as comonomer decreases the emission from the BT unit (around $500 \mathrm{~nm}$ ), probably caused by energy transfer from the BT unit to TBT. Excitation spectra recorded at $607 \mathrm{~nm}$ of $\mathrm{BT}(1 \%)_{\text {random }} \mathrm{TBT}(1 \%)_{\text {random }}$ as dispersion show a weak peak around $430 \mathrm{~nm}$ (Figure S40), due to the contribution from the BT units, this agrees with the low loading of BT in the polymer. Considering the low relative intensity of the peak at $500 \mathrm{~nm}$ in $\mathrm{BT}(1 \%)_{\text {random }} \mathrm{TBT}(1 \%)_{\text {random }}$ as PEG dispersion and the slightly increase of the amplification of the emission at $607 \mathrm{~m}$, from the TBT unit compare to polymer TBT $(1 \%)_{\text {random }}$ we hypothesized there would be an energy transfer flow from the polyphenylene network to the BT unit and from there to the TBT unit.

As shown by these results, the degree of interaction between acceptor comonomers could be tuned by changing the polymer addition sequence in the synthesis. In $\mathrm{BT}(1 \%)_{\text {core }} \mathrm{TBT}(1 \%)_{\text {shell }}$, the interaction between BT and TBT should be weaker because the acceptors are embedded in different domains. For $\operatorname{TBT}(1 \%)_{\text {core }} \mathrm{BT}(1 \%)_{\text {shell, }}$ the emission spectrum is similar to the one from $\operatorname{TBT}(1 \%)_{\text {core, }}$ with two main peaks, pointing in a stronger interaction between $\mathrm{BT}$ and TBT in different domains than in $\mathrm{BT}(1 \%)_{\text {core }} \mathrm{TBT}(1 \%)_{\text {shell }}$. A bigger change is observed in $\mathrm{BT}(1 \%)_{\text {random }} \mathrm{TBT}(1 \%)_{\text {surface, }}$ where the main peak is now at $511 \mathrm{~nm}$, emission from BT units. This result suggests that in the structure $A_{\text {random }} B_{\text {surface }}$ the interaction between BT and TBT is weaker than in $A_{\text {core }} B_{\text {shell, because of the different }}$ disposition of the acceptor in the material. And even a bigger difference is observed in the emission spectra of $\mathrm{BT}(1 \%)_{\text {core }} \mathrm{TBT}(1 \%)_{\text {surface, }}$ with a main peak at $510 \mathrm{~nm}$ and a minor contribution around $600 \mathrm{~nm}$ from TBT emission, where the effect of the distance between acceptors is dramatic.

When the same study was carried using a loading ratio of 0.5 mol \% for BT and TBT, a comparable behavior was found along the series. Photoluminescence spectra in solid state of polymers CP-CMP BT $(0.5 \%)_{\text {random }} \mathrm{TBT}(0.5 \%)_{\text {random }}$, $\mathrm{BT}(0.5 \%)_{\text {core }} \mathrm{TBT}(0.5 \%)_{\text {shell }}, \mathrm{TBT}(0.5 \%)_{\text {core }} \mathrm{BT}(0.5 \%)_{\text {shell }}$, $\operatorname{TBT}(0.5 \%)_{\text {random }} \mathrm{BT}(0.5 \%)_{\text {surface, }}$ and $\operatorname{TBT}(0.5 \%)_{\text {core }} \mathrm{BT}$ $(0.5 \%)_{\text {surface }}$ show a main emission peak at around $600 \mathrm{~nm}$, but for BT $(0.5 \%)_{\text {random }}$ TBT $(0.5 \%)_{\text {surface }}$ and $\mathrm{BT}(0.5 \%)_{\text {core- }} \mathrm{TBT}(0.5 \%)_{\text {surface }}$ the emission is centered at 515 $\mathrm{nm}$ (Figure S41). In dispersion in PEG, the relative intensity of the different peaks changes in the same fashion as when the loading of acceptors was $1 \mathrm{~mol} \%$ (Figure S42).

We also prepared a series of example with a lower loading of the acceptor $(0.1 \mathrm{~mol} \%)$ where the influence of the additional 


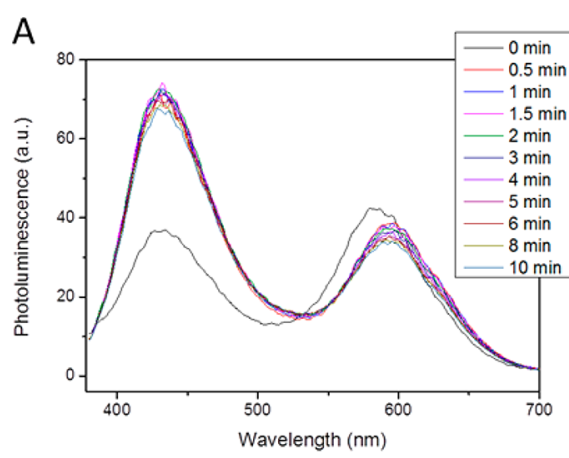

D

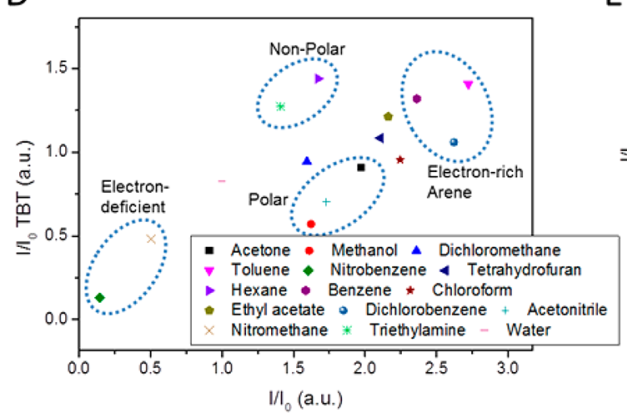

B

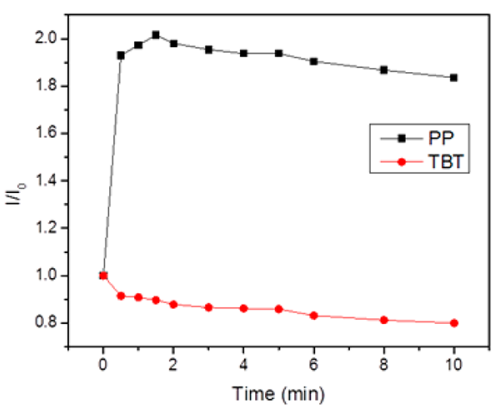

E

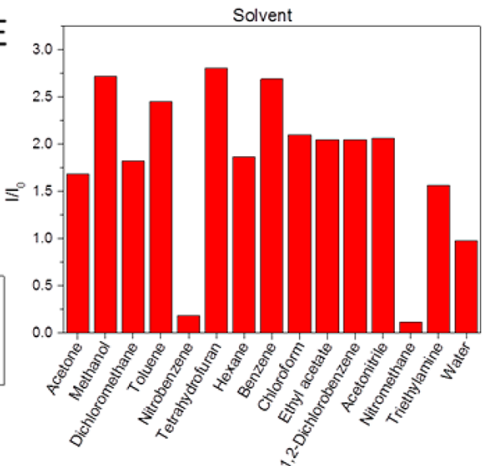

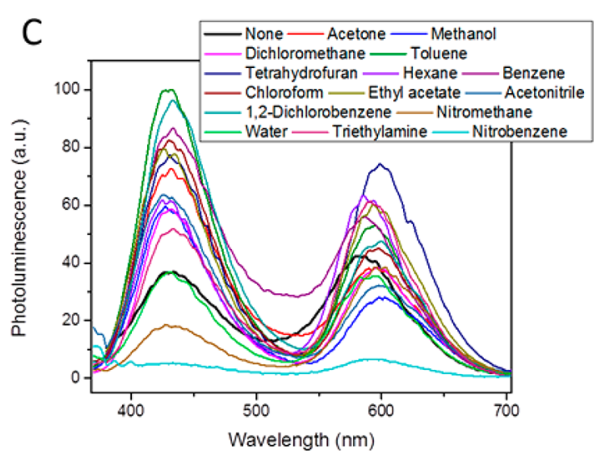

F

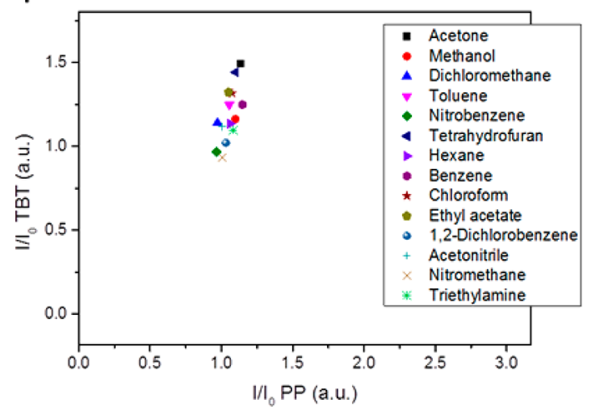

Figure 9. (A) Photoluminescence spectral changes of a thin film of CP-CMP4a upon exposure to acetone. (B) Time-dependent changes in the intensity of the emission peaks from polyphenylene (PP) and TBT in the photoluminescence spectra of CP-CMP4a upon exposure to acetone. (C) Photoluminescence of a thin film of CP-CMP4a upon exposure to different solvent vapor for $1 \mathrm{~min}$. (D) 2D map of VOC recognition of CP-CMP4a based in the change of the intensity of the both emission peaks (PP and TBT). Data were taken after 1 min of exposure to analyte vapor at room temperature. (E) Bar-diagram of solvents based on the emission response of CP-CMP0. (F) 2D map of VOC recognition of LP-4 based in the change of the intensity of the both emission peaks (PP and TBT). $\lambda_{\mathrm{exc}}=360 \mathrm{~nm}$.

sequence is still present but less intense than in the already discussed polymers (Figures S43 and 44).

Analogous two-step synthesis for polymers $\mathrm{BT}(1 \%)_{\text {random }} \mathrm{TBT}(1 \%)_{\text {surface }}$ and $\mathrm{TBT}(1 \%)_{\text {random }} \mathrm{BT}(1 \%)_{\text {surface }}$ were used to check the influence of the reaction conditions. The polymers obtained in a two-step fashion show slightly different emission spectra to the ones synthesized in one pot (Figures S51-S54).

Again, as in CP-CMP3,4, we carried a series of experiment mixing polymers CP-CMP01, BT $(1 \%)_{\text {random }}$ and $\operatorname{TBT}(1 \%)_{\text {random }}$ in dispersion and solid state with the all possible combinations to check the nature of the energy transfer (Figures S55 and S56). From the all experiments carried out, no obvious fluorescence interparticle energy transfer could be observed in dispersion neither solid state, suggesting an intraparticle energy transfer process for all these polymers.

Regarding microporosity, polymers prepared using different sequential addition did not show a strong change in surface area. Polymers with domain structure $\mathrm{A}_{\text {core }} \mathrm{B}_{\text {shell }}$, $\mathrm{BT}(1 \%)_{\text {core }} \mathrm{TBT}(1 \%)_{\text {shell }}$ and $\mathrm{TBT}(1 \%)_{\text {core }} \mathrm{BT}(1 \%)_{\text {shell }}$, showed a surface area of 806 and $681 \mathrm{~m}^{2} \mathrm{~g}^{-1}$, respectively. Polymers with a domain structure $\mathrm{A}_{\text {random }} \mathrm{B}_{\text {surface }} \mathrm{BT}(1 \%)_{\text {random }} \mathrm{TBT}$ $(1 \%)_{\text {surface }}$ and $\mathrm{TBT}(1 \%)_{\text {random }} \mathrm{BT}(1 \%)_{\text {surface, }}$ have a surface area of 787 and $998 \mathrm{~m}^{2} \mathrm{~g}^{-1}$. The different reaction conditions used in the synthesis of these polymers does not affect to the degree of microporosity of these amorphous networks.

During the isolation and characterization of these CMPs, we observed changes on the fluorescence when some polymers were in contact with different solvents. This encouraged us to study the use of these materials as fluorescence sensors for volatile organic compounds (VOCs). There are already some reports of CMPs as fluorescence sensors for volatile organic compounds in vapor phase. ${ }^{11,49-54}$ We decide to study the fluorescence spectral changes of a thin film of polymer CPCMP4a upon exposure to solvent vapor. Initially, we chose this polymer because its solid-state fluorescence spectrum shows two clear emission peaks, what would provide two coordinates to build a 2D map for the VOCs. The time-dependent photoluminescence of a thin film ${ }^{55}$ of CP-CMP4a in contact with solvent vapors was carried in situ by the addition of approximately $10 \mu \mathrm{L}$ of solvent to the cuvette containing the polymer sample film (see the Supporting Information). ${ }^{56}$ For example, after addition of $10 \mu \mathrm{L}$ of acetone to a cuvette holding a thin film of CP-CMP4a, the photoluminescence spectrum changed drastically, such that the emission peak centered at 420 $\mathrm{nm}$ due to the polyphenylene (PP) domain increased its intensity 1.9 fold after 0.5 min exposure, and then it rose 2 fold after $1 \mathrm{~min}$. The emission peak at around $590 \mathrm{~nm}$ associated with the TBT unit decreased its intensity 0.9 fold, and decreased slowly with time to 0.8 fold (Figures 9A). Also, this emission peak associated with TBT units experiences a redshift of $11 \mathrm{~nm}$ after the exposure of the polymer film to acetone vapor. Figure 9B represents the variation of the ratio of the intensity of both emission peaks of CP-CMP4a with time, showing a stable photoluminescence after just $1 \mathrm{~min}$ of exposure what indicates the fast response of this material to acetone vapor. The same experiments were carried out using other 14 solvents including water, see Figures S86-89. The photoluminescence spectral change of CP-CMP4a in the solid state depends of the nature of the solvent, so polar solvents such as methanol or acetonitrile increased the intensity of the 
emission peak associated with PP and decreased the one associated with TBT. Electron-rich aromatic solvents as toluene or benzene increased the intensity of both peaks (PP and TBT), and electron-deficient solvent as nitromethane or nitrobenzene decreased the intensity of both emission peaks. Figure 9C summarizes the fluorescence spectral changes of CPCMP4a as thin film after $1 \mathrm{~min}$ exposure to different solvents. Plotting $I / I_{0}$ for both emission peaks allows to generate a $2 \mathrm{D}$ map for the qualitative identification of solvents (Figure 9D), where several regions can be drawn for the chemical nature of the solvent. The quenching of the photoluminescence after exposure to electron-deficient analyte vapors can be explain based on an electron-transfer mechanism from the conduction band of polymer to the lowest unoccupied molecular orbital (LUMO) of the nitro compound. ${ }^{57,58}$ The enhancement in the emission after exposure to vapor of non-electron-deficient VOC could be due to a swelling effect of the solvent onto the polymer network, similar to the effect in the photoluminescence of these polymers described before from solid state to PEG dispersion.

Similar in situ time-dependent photoluminescence experiments of CP-CMP4b in contact with solvent vapors were carried out with thin film samples (Figures S92-S95). Analogous responses of the emission peaks from the photoluminescence spectra of the thin film were found (see the Supporting Information). From the data taken after $1 \mathrm{~min}$ of exposure to the analyte vapor, a 2D map was generated for CPCMP4b, showing a similar distribution of the solvents to that obtained from CP-CMP4a (Figure S96). We also studied the response of thin film samples of CP-CMP0, the undoped native polymer, to the exposure of the vapor analytes (Figures S98S101). After exposure to solvent vapors, the emission peak at around $440 \mathrm{~nm}$ in CP-CMP0 in solid state behaves analogously to the emission peak associated with PP in CP-CMP4a, quenched by electron-deficient solvents and enhancement by nonelectron-deficient solvents. As expected, CP-CMP0 only has one emission peak and its change after exposure to vapors did not allow building a 2D map (Figure 9E).

Once again, to illustrate the importance of microporosity in these CP-CMP $4 s$ as fluorescence sensors, we studied the photoluminescence spectral changes of nonporous linear polymer LP4. Figures S103-S106 show the time-dependent fluorescence spectra upon analyte vapor exposure, where a less dramatic change can be appreciated compared with CP-CMP $4 \mathrm{~s}$. Although some of the fluorescence signal showed some fluctuation after $1 \mathrm{~min}$ of exposure, the $2 \mathrm{D}$ map produced from data taken at $1 \mathrm{~min}$ from both emission peaks (PP and TBT) showed a less pronounced distribution compared to CPCMP4a(Figure 9F). This indicates that the microporosity can be beneficial in a fluorescence sensor, allowing a better response in the photoluminescence after analyte vapor exposure, most likely due to the high-surface-area skeleton improving the contact between polymer and vapor analyte, ${ }^{11}$ as well as the increased fluorescence quantum yield mentioned above.

The influence of domain formation was also studied in the sensor response with the study of the time-dependent photoluminescence spectral change of thin film samples of CP-CMP TBT $(0.5 \%)_{\text {surface }}$ upon contact to solvent vapors (Figures S108-S111). As shown in the Supporting Information, the emission peak around $440 \mathrm{~nm}$ associated with PP experiences changes in the same degree than polymer CPCMP4a, but the emission peak centered at $580 \mathrm{~nm}$ shows smaller changes after exposure to different solvent. So in the $2 \mathrm{D}$ map built from $1 \mathrm{~min}$ data for CP-CMP TBT $(0.5 \%)_{\text {surface, }}$ the solvent points are less well spread than for CP-CMP4a.

Finally, these thin film CMPs can be reused for sensing of analyte vapor. Cycling tests were carried for CP-CMP4a, CP$\mathrm{CMP} 4 \mathrm{~b}$ and CP-CMP0 using methanol and nitromethane as analytes (Figures S114-S116). The intensity of the emission peaks can be recovered after every cycle with only a small loss of the signal after four cycles.

\section{CONCLUSIONS}

In summary, we have developed a new method to fine-tune the optical band gap and the emission of conjugated microporous polyphenylene networks by inclusion of small amount of a dopant comonomer as chromophore in the network. The degree of tuning can be modulated through the use of different acceptors and their feed ratios. The intrinsic microporosity of these materials increases the absolute fluorescence quantum yield in solid state. This method has been proved as an efficient strategy to synthesize white emitting CMPs, controlling the emission of the material through a wide range. Moreover, we studied the formation of domains in the polymer network by varying the addition sequence during the synthesis. These domains have a crucial effect in the flow of energy through the network what drove to a change in the emission spectra. Finally we report the use of CMPs containing TBT chromophores as fluorescence sensor for volatile organic compounds. The changes in the dual emission of thin film samples of these polymers allow the creation of $2 \mathrm{D}$ map for the recognition of different solvents. The methods reported here enable the tuning of the photophysical properties of conjugated microporous polymers, which is central to the application of these materials. ${ }^{59}$ More broadly, the detailed understanding of energy transfer in these networks may be key to designing function in other materials, such as organic photocatalysts.

\section{ASSOCIATED CONTENT}

\section{Supporting Information}

The Supporting Information is available free of charge on the ACS Publications website at DOI: 10.1021/acs.chemmater.6b01195.

Full synthetic details and analysis for the polymers, FTIR, gas sorption, UV/PL spectra, SEM data, and sensor experiments (PDF)

\section{AUTHOR INFORMATION}

\section{Corresponding Author}

*E-mail: aicooper@liverpool.ac.uk.

\section{Author Contributions}

The manuscript was written through contributions of all authors. All authors have given approval to the final version of the manuscript.

\section{Funding}

We thank EPSRC (EP/C511794/1 and EP/N004884/1) for funding.

\section{Notes}

The authors declare no competing financial interest.

\section{ACKNOWLEDGMENTS}

We thank Dr. Benjamin J. Slater and Prof. Dave J. Adams for helpful discussions. Dr. Lin Chen, Dr. Tom Hasell, Dr. Shan 
Jiang, and Dr. Tobias Heil are acknowledged for help with electron microscopy.

\section{ABBREVIATIONS}

$\mathrm{CMP}$, conjugated microporous polymer

BT, benzothiadiazole

TBT, bisthiophenebenzothiadiazole

PDI, perylenediimide

$\mathrm{CP}$, copolymer

VOC, volatile organic compound

$\mathrm{PP}$, polyphenylene

$\mathrm{LP}$, linear polymer

\section{REFERENCES}

(1) Jiang, J.-X.; Su; Trewin, A.; Wood, C. D.; Campbell, N. L.; Niu, H.; Dickinson, C.; Ganin, A. Y.; Rosseinsky, M. J.; Khimyak, Y. Z.; Cooper, A. I. Conjugated Microporous Poly(Aryleneethynylene) Networks. Angew. Chem., Int. Ed. 2007, 46, 8574-8578.

(2) Cooper, A. I. Conjugated Microporous Polymers. Adv. Mater. 2009, 21, 1291-1295.

(3) Dawson, R.; Cooper, A. I.; Adams, D. J. Nanoporous Organic Polymer Networks. Prog. Polym. Sci. 2012, 37, 530-563.

(4) Xu, Y.; Jin, S.; Xu, H.; Nagai, A.; Jiang, D. Conjugated Microporous Polymers: Design, Synthesis and Application. Chem. Soc. Rev. 2013, 42, 8012-8031.

(5) Liu, Q.; Tang, Z.; Wu, M.; Zhou, Z. Design, Preparation and Application of Conjugated Microporous Polymers. Polym. Int. 2014, 63, 381-392.

(6) Zhang, Y.; Ying, J. Y. Main-Chain Organic Frameworks with Advanced Catalytic Functionalities. ACS Catal. 2015, 5, 2681-2691.

(7) Xie, Y.; Wang, T.-T.; Liu, X.-H.; Zou, K.; Deng, W.-Q. Capture and Conversion of $\mathrm{CO}_{2}$ at Ambient Conditions by a Conjugated Microporous Polymer. Nat. Commun. 2013, 4, 2960-2960.

(8) Sheng, X.; Guo, H.; Qin, Y.; Wang, X.; Wang, F. A Novel Metalloporphyrin-Based Conjugated Microporous Polymer for Capture and Conversion of $\mathrm{CO}_{2}$. RSC $A d v$. 2015, 5, 31664-31669.

(9) Lindemann, P.; Tsotsalas, M.; Shishatskiy, S.; Abetz, V.; KrollaSidenstein, P.; Azucena, C.; Monnereau, L.; Beyer, A.; Goelzhaeuser, A.; Mugnaini, V.; Gliemann, H.; Braese, S.; Woell, C. Preparation of Freestanding Conjugated Microporous Polymer Nanomembranes for Gas Separation. Chem. Mater. 2014, 26, 7189-7193.

(10) Qiao, S.; Du, Z.; Yang, R. Design and Synthesis of Novel Carbazole-Spacer-Carbazole Type Conjugated Microporous Networks for Gas Storage and Separation. J. Mater. Chem. A 2014, 2, 18771885 .

(11) Liu, X.; Xu, Y.; Jiang, D. Conjugated Microporous Polymers as Molecular Sensing Devices: Microporous Architecture Enables Rapid Response and Enhances Sensitivity in Fluorescence-on and Fluorescence-Off Sensing. J. Am. Chem. Soc. 2012, 134, 8738-8741.

(12) Zhang, Y.; A, S.; Zou, Y.; Luo, X.; Li, Z.; Xia, H.; Liu, X.; Mu, Y. Gas Uptake, Molecular Sensing and Organocatalytic Performances of a Multifunctional Carbazole-Based Conjugated Microporous Polymer. J. Mater. Chem. A 2014, 2, 13422-13430.

(13) Kou, Y.; Xu, Y.-H.; Guo, Z.-Q.; Jiang, D.-L. Supercapacitive Energy Storage and Electric Power Supply Using an Aza-Fused ПConjugated Microporous Framework. Angew. Chem., Int. Ed. 2011, 50, 8753-8757.

(14) Xu, F.; Chen, X.; Tang, Z.; Wu, D.; Fu, R.; Jiang, D. RedoxActive Conjugated Microporous Polymers: A New Organic Platform for Highly Efficient Energy Storage. Chem. Commun. 2014, 50, 47884790.

(15) Chen, L.; Yang, Y.; Jiang, D. Cmps as Scaffolds for Constructing Porous Catalytic Frameworks: A Built-in Heterogeneous Catalyst with High Activity and Selectivity Based on Nanoporous Metalloporphyrin Polymers. J. Am. Chem. Soc. 2010, 132, 9138-9143.

(16) Jiang, J.-X.; Wang, C.; Laybourn, A.; Hasell, T.; Clowes, R.; Khimyak, Y. Z.; Xiao, J.; Higgins, S. J.; Adams, D. J.; Cooper, A. I.
Metal-Organic Conjugated Microporous Polymers. Angew. Chem., Int. Ed. 2011, 50, 1072-1075.

(17) Jiang, J.-X.; Li, Y.; Wu, X.; Xiao, J.; Adams, D. J.; Cooper, A. I. Conjugated Microporous Polymers with Rose Bengal Dye for Highly Efficient Heterogeneous Organo-Photocatalysis. Macromolecules 2013, 46, 8779-8783.

(18) Weber, J.; Thomas, A. Toward Stable Interfaces in Conjugated Polymers: Microporous Poly(P-Phenylene) and Poly(Phenyleneethynylene) Based on a Spirobifluorene Building Block. J. Am. Chem. Soc. 2008, 130, 6334-6335.

(19) Brandt, J.; Schmidt, J.; Thomas, A.; Epping, J. D.; Weber, J. Tunable Absorption and Emission Wavelength in Conjugated Microporous Polymers by Copolymerization. Polym. Chem. 2011, 2, $1950-1952$.

(20) Jiang, J.-X.; Trewin, A.; Adams, D. J.; Cooper, A. I. Band Gap Engineering in Fluorescent Conjugated Microporous Polymers. Chem. Sci. 2011, 2, 1777-1781.

(21) Sprick, R. S.; Jiang, J.-X.; Bonillo, B.; Ren, S.; Ratvijitvech, T.; Guiglion, P.; Zwijnenburg, M. A.; Adams, D. J.; Cooper, A. I. Tunable Organic Photocatalysts for Visible-Light-Driven Hydrogen Evolution. J. Am. Chem. Soc. 2015, 137, 3265-3270.

(22) Vyas, V. S.; Lotsch, B. V. Materials Chemistry Organic Polymers Form Fuel from Water. Nature 2015, 521, 41-42.

(23) Jung, I. H.; Kim, S. H.; Jeong, E.; Yang, R.; Lee, K.; Woo, H. Y.; Shim, H.-K. Synthesis and Characterization of Fluorene and Cyclopentadithiophene-Based Copolymers Exhibiting Broad Absorption for Photovoltaic Devices. J. Polym. Sci., Part A: Polym. Chem. 2011, 49, 1248-1255.

(24) Liu, P.; Li, S.; Jin, Y.; Qian, L.; Gao, N.; Yao, S. Q.; Huang, F.; $\mathrm{Xu}$, Q.-H.; Cao, Y. Red-Emitting Dpsb-Based Conjugated Polymer Nanoparticles with High Two-Photon Brightness for Cell Membrane Imaging. ACS Appl. Mater. Interfaces 2015, 7, 6754-6763.

(25) Zhou, J.; Xie, S.; Amond, E. F.; Becker, M. L. Tuning Energy Levels of Low Bandgap Semi-Random Two Acceptor Copolymers. Macromolecules 2013, 46, 3391-3394.

(26) Chen, L.; Honsho, Y.; Seki, S.; Jiang, D. Light-Harvesting Conjugated Microporous Polymers: Rapid and Highly Efficient Flow of Light Energy with a Porous Polyphenylene Framework as Antenna. J. Am. Chem. Soc. 2010, 132, 6742-6748.

(27) Xu, Y.-H.; Chen, L.; Guo, Z.-Q.; Nagai, A.; Jiang, D.-L. LightEmitting Conjugated Polymers with Microporous Network Architecture: Interweaving Scaffold Promotes Electronic Conjugation, Facilitates Exciton Migration, and Improves Luminescence. J. Am. Chem. Soc. 2011, 133, 17622-17625.

(28) Chen, Q.; Wang, J.-X.; Yang, F.; Zhou, D.; Bian, N.; Zhang, X.J.; Yan, C.-G.; Han, B.-H. Tetraphenylethylene-Based Fluorescent Porous Organic Polymers: Preparation, Gas Sorption Properties and Photoluminescence Properties. J. Mater. Chem. 2011, 21, 1355413560.

(29) Lavigne, J. J.; Broughton, D. L.; Wilson, J. N.; Erdogan, B.; Bunz, U. H. F. "Surfactochromic" Conjugated Polymers: Surfactant Effects on Sugar-Substituted Ppes. Macromolecules 2003, 36, 74097412.

(30) Wrighton, M. S.; Ginley, D. S.; Morse, D. L. Technique for the Determination of Absolute Emission Quantum Yields of Powdered Samples. J. Phys. Chem. 1974, 78, 2229-2233.

(31) Yang, J.-S.; Swager, T. M. Porous Shape Persistent Fluorescent Polymer Films: An Approach to TNT Sensory Materials. J. Am. Chem. Soc. 1998, 120, 5321-5322.

(32) Traiphol, R.; Charoenthai, N.; Srikhirin, T.; Kerdcharoen, T.; Osotchan, T.; Maturos, T. Chain Organization and Photophysics of Conjugated Polymer in Poor Solvents: Aggregates, Agglomerates and Collapsed Coils. Polymer 2007, 48, 813-826.

(33) Cyriac, A.; Amrutha, S. R.; Jayakannan, M. Renewable ResourceBased Poly (M-Phenylenevinylene)S and Their Statistical Copolymers: Synthesis, Characterization, and Probing of Molecular Aggregation and Forster Energy Transfer Processes. J. Polym. Sci., Part A: Polym. Chem. 2008, 46, 3241-3256. 
(34) Davies, M. L.; Douglas, P.; Burrows, H. D.; da Graca Miguel, M.; Douglas, A. Effect of Aggregation on the Photophysical Properties of Three Fluorene-Phenylene-Based Cationic Conjugated Polyelectrolytes. J. Phys. Chem. B 2011, 115, 6885-6892.

(35) Cordovilla, C.; Swager, T. M. Strain Release in Organic Photonic Nanoparticles for Protease Sensing. J. Am. Chem. Soc. 2012, 134, 6932-6935.

(36) Laybourn, A.; Dawson, R.; Clowes, R.; Hasell, T.; Cooper, A. I.; Khimyak, Y. Z.; Adams, D. J. Network Formation Mechanisms in Conjugated Microporous Polymers. Polym. Chem. 2014, 5, 63256333.

(37) Lakowicz, J. R. Principles of Fluorescence Spectroscopy, 3rd ed.; Springer: Berlin, 2006.

(38) Huang, J.; Wu, Y.; Fu, H.; Zhan, X.; Yao, J.; Barlow, S.; Marder, S. R. Photoinduced Intramolecular Electron Transfer in Conjugated Perylene Bisimide-Dithienothiophene Systems: A Comparative Study of a Small Molecule and a Polymer. J. Phys. Chem. A 2009, 113, 50395046.

(39) Reineke, S.; Thomschke, M.; Luessem, B.; Leo, K. White Organic Light-Emitting Diodes: Status and Perspective. Rev. Mod. Phys. 2013, 85, 1245-1293.

(40) Liu, J.; Yee, K.-K.; Lo, K. K.-W.; Zhang, K. Y.; To, W.-P.; Che, C.-M.; Xu, Z. Selective Ag(I) Binding, H2s Sensing, and White-Light Emission from an Easy-to-Make Porous Conjugated Polymer. J. Am. Chem. Soc. 2014, 136, 2818-2824.

(41) Zhang, P.; Wu, K.; Guo, J.; Wang, C. From Hyperbranched Polymer to Nanoscale CMP (NCMP): Improved Microscopic Porosity, Enhanced Light Harvesting, and Enabled Solution Processing into White-Emitting Dye@NCMP Films. ACS Macro Lett. 2014, 3, $1139-1144$.

(42) Zhu, M.; Zou, J.; Hu, S.; Li, C. g.; Yang, C.; Wu, H.; Qin, J.; Cao, Y. Highly Efficient Single-Layer White Polymer Light-Emitting Devices Employing Triphenylamine-Based Iridium Dendritic Complexes as Orange Emissive Component. J. Mater. Chem. 2012, 22, 361-366.

(43) Sudyoadsuk, T.; Moonsin, P.; Prachumrak, N.; Namuangruk, S.; Jungsuttiwong, S.; Keawin, T.; Promarak, V. Carbazole Dendrimers Containing Oligoarylfluorene Cores as Solution-Processed HoleTransporting Non-Doped Emitters for Efficient Pure Red, Green, Blue and White Organic Light-Emitting Diodes. Polym. Chem. 2014, 5, 3982-3993.

(44) Shih, H.-M.; Wu, R.-C.; Shih, P.-I.; Wang, C.-L.; Hsu, C.-S. Synthesis of Fluorene-Based Hyperbranched Polymers for SolutionProcessable Blue, Green, Red, and White Light-Emitting Devices. J. Polym. Sci., Part A: Polym. Chem. 2012, 50, 696-710.

(45) Kim, J.; Park, J.; Jin, S.-H.; Lee, T. S. Synthesis of Conjugated, Hyperbranched Copolymers for Tunable Multicolor Emissions in Light-Emitting Diodes. Polym. Chem. 2015, 6, 5062-5069.

(46) Emission spectra were corrected according to the method reported in ref 37 . But even after careful corrections are made, the results are only accurate to $\pm 10 \%$, which would explain the disagreement between CIE coordinates and the actual color.

(47) Throughout this discussion, the terms "core" and "shell" refer to separate chromophore domains, but those may not exist as idealized core-shell structures, as in this simple schematic representation.

(48) Xu, Y.; Nagai, A.; Jiang, D. Core-Shell Conjugated Microporous Polymers: A New Strategy for Exploring Color-Tunable and -Controllable Light Emissions. Chem. Commun. 2013, 49, 1591-1593.

(49) Gopalakrishnan, D.; Dichtel, W. R. Direct Detection of RDX Vapor Using a Conjugated Polymer Network. J. Am. Chem. Soc. 2013, 135, 8357-8362.

(50) Novotney, J. L.; Dichtel, W. R. Conjugated Porous Polymers for TNT Vapor Detection. ACS Macro Lett. 2013, 2, 423-426.

(51) Wu, X.; Li, H.; Xu, Y.; Xu, B.; Tong, H.; Wang, L. Thin Film Fabricated from Solution-Dispersible Porous Hyperbranched Conjugated Polymer Nanoparticles without Surfactants. Nanoscale 2014, 6, 2375-2380.
(52) Gopalakrishnan, D.; Dichtel, W. R. Real-Time, Ultrasensitive Detection of RDX Vapors Using Conjugated Network Polymer Thin Films. Chem. Mater. 2015, 27, 3813-3816.

(53) Ma, H.; Li, B.; Zhang, L.; Han, D.; Zhu, G. Targeted Synthesis of Core-Shell Porous Aromatic Frameworks for Selective Detection of Nitro Aromatic Explosives Via Fluorescence Two-Dimensional Response. J. Mater. Chem. A 2015, 3, 19346-19352.

(54) Yuan, K.; Guo-Wang, P.; Hu, T.; Shi, L.; Zeng, R.; Forster, M.; Pichler, T.; Chen, Y.; Scherf, U. Nanofibrous and GrapheneTemplated Conjugated Microporous Polymer Materials for Flexible Chemosensors and Supercapacitors. Chem. Mater. 2015, 27, 74037411.

(55) Lan, A.; Li, K.; Wu, H.; Olson, D. H.; Emge, T. J.; Ki, W.; Hong, M.; Li, J. A Luminescent Microporous Metal-Organic Framework for the Fast and Reversible Detection of High Explosives. Angew. Chem., Int. Ed. 2009, 48, 2334-2338.

(56) Yi, F.-Y.; Wang, Y.; Li, J.-P.; Wu, D.; Lan, Y.-Q.; Sun, Z.-M. An Ultrastable Porous Metal-Organic Framework Luminescent Switch Towards Aromatic Compounds. Mater. Horiz. 2015, 2, 245-251.

(57) McQuade, D. T.; Pullen, A. E.; Swager, T. M. Conjugated Polymer-Based Chemical Sensors. Chem. Rev. 2000, 100, 2537-2574.

(58) Thomas, S. W., III; Joly, G. D.; Swager, T. M. Chemical Sensors Based on Amplifying Fluorescent Conjugated Polymers. Chem. Rev. 2007, 107, 1339-1386.

(59) Müllen, K. Molecular Defects in Organic Materials. Nature Reviews Materials 2016, 1, 15013. 